\title{
Modelling and Simulation of Friction Stir Welding and Under Water Friction Stir Welding of Al6063 Alloy
}

\author{
P. Vamsi Krishna ${ }^{1, *}$, Amol Balasaheb Jaware ${ }^{1}$, R. R. Srikant ${ }^{2}$ \\ ${ }^{1}$ Department of Mechanical Engineering, National Institute of Technology Warangal, India \\ ${ }^{2}$ Department of Technology, University of Northern Iowa, USA.
}

Received October 21, 2019; Revised December 30, 2019; Accepted January 13, 2020

Copyright $\odot 2020$ by authors, all rights reserved. Authors agree that this article remains permanently open access under the terms of the Creative Commons Attribution License 4.0 International License

\begin{abstract}
Friction stir welding (FSW) is a solid-state welding process that is gaining importance in recent times due to better control of microstructure. In the present work, a thermo-mechanical model is developed for FSW and under water friction stir welding (UFSW) of AA 6063-T6. Temperature dependent viscosity is considered as thermo physical property along with constant values of thermal conductivity and specific heat. Fine mesh is used for complex parts of tool to obtain good results. Rotational speed of tool, feed rate and plunge pressure are taken as influencing parameters for study. Partial stick-slip boundary condition is taken between the tool and work piece interfaces. Experiments were carried out for validation of model. The results of thermal and material flow histories are extracted. Results shows the significant differences in peak temperature of FSW and UFSW along with reduction in heat affected zone in UFSW whereas results of material flow velocity underlined the differences between the FSW and UFSW in term of peak values of stir velocities with the change in influencing parameters.
\end{abstract}

Keywords FSW, UFSW, Modelling, Heat Affected Zone

\section{Introduction}

Welding employs heat and/or pressure to achieve a sound joint. Friction stir welding (FSW) is the non-fusion solid-state welding process that uses both heat and pressure. Simultaneously rotating and translating non-consumable tool is used during the process. Motion of the tool causes heat generation and flow of material [1]. Material converts from solid to visco-plastic state because of heat generated due to the friction in between the tool and workpiece. This visco-plastic material starts flowing from front of the tool to back of tool and form a joint by accumulating the cavity created by tool. Under water friction stir welding (UFSW) is recent welding technique in friction welding technology. Material to be welded is completely immersed inside the water, which acts as working environment. Heat transfer between water and work material gives the fine grain structure of welded component. The size of heat-affected and Thermo-mechanically affected zones get reduced in UFSW [2]. AA 6063-T6 is used for extrusion and fabrication of high width to thickness ratio panels used in high speed trains and ships. It also has applications in balustrading rails and posts [3].

Ugender et al [4] investigated the effect of tool geometry on mechanical properties of AA2014. It is concluded from investigation that taper cylindrical tool profile with $3 \mathrm{~mm}$ radius of curvature gives the better mechanical properties like tensile strength, hardness etc. than strait cylindrical tool profile. Singh et al [5] studied FSW joints of AZ31B$\mathrm{O} \mathrm{Mg}$ alloy and the effects of different welding parameters Rotation speed, feed rate and shoulder diameter were taken as influencing parameters. Fracture occurred between the stir zone and thermo-mechanically affected zone. Dynamic recrystallization of material lead to fine grain structure. High tensile strength of joint is observed at $0.05 \mathrm{~mm} / \mathrm{rev}$ and $20 \mathrm{~mm}$ shoulder diameter. Shah et al [6] experimentally investigated the temperature distribution and joint properties of A1 7075 T651 friction stir welded aluminium alloys. They concluded that joints made with $20 \mathrm{~mm}$ shoulder diameter yield maximum joint efficiency. Advancing side temperatures are higher than the retreating side temperatures. Sharma et al [7] analysed the FSW of dissimilar alloys A16061 and Mg AZ31 at different process parameters. Rotation speeds in the range of 800-2000 rpm are used with feed rate of $10-40 \mathrm{~mm} / \mathrm{min}$. The influence of process parameters is studied on weld strength. Rotation speed of $1200 \mathrm{rpm}$ and feed rate of $10 \mathrm{~mm} / \mathrm{min}$ were identified as most influential parameters. Mohammadi et al [8] studied the effect of tool geometry, rotation speed and feed rate on properties of dissimilar magnesium/ aluminium friction stir welded lap joints. They observed 
that increase in rotation speed to $1400 \mathrm{rpm}$ and feed rate to $40 \mathrm{~mm} / \mathrm{min}$ respectively, tensile strength and ductility of joint increases. Inter-metallic compounds formation at $1400 \mathrm{rpm}$ results in higher strength than the softer and ductile base material. Zhang et al [9] created numerical model for FSW process taking cylindrical tool and conical tool with different shoulder diameters and tool diameters and investigated effect of shoulder diameter and pin diameter on Heat generation and material flow. Decrease by $55.6 \%$ in shoulder-plate contact area, the input power is decreased by $46.1 \%$. The shoulder diameter variation results in more change in energy than pin diameter variation. Ramanjaneyulu et al [10] presents the formulation of a mathematical model with process parameters and tool geometry to predict the responses of friction stir welds 2014-T6 aluminium alloy. The most influential process parameters considered are spindle speed, welding speed, tilt angle and tool pin profile. Heat input to the weld increase with increase in rotation speed of tool and reduction in feed rate of tool. Superior tensile properties compared to other joints are shown by the joints made with hexagon pin profile at $1000 \mathrm{rpm}, 800 \mathrm{~mm} / \mathrm{min}$ and tilt angle of 3.5. Hexagon tool profile with $1000 \mathrm{rpm}$ rotation speed, $800 \mathrm{~mm} / \mathrm{min}$ feed rate and 3.5 tilt angle shows the optimum mechanical properties. Su et al [11] Designed a model for calculating friction coefficient, slip rate, Heat generation and heat density for conical and Tri flat pin tool. It is found that the "stir action" of Triflat pin tool is more than Conical pin tool. Hua Wang et al [12] gives the tool contact condition investigation on aerospace aluminium alloy. The new contact condition between tool and workpiece which leads to reasonable heat generation is suggested in investigation. Heat generation decreases in slip boundary condition than in stick boundary condition. Discrepancies occurs in temperature distribution when slip coefficient value is less in slip condition. Colegrove et al [13] studied the material flow around the threaded tool pin in FSW. Threaded tool that has a rake angle 2.5 away from direction of travel is used for study. All isothermal and viscous heat generation models predicted the material moved along the swept along the receding side of the tool. It was observed that the temperature and power were over estimated. Bhattacharya et al [14] analysed the effect of influencing parameters on material flow, mechanical properties and intermetallic characterization of AA6063 and HCP copper FSW joint. Rotation speed of $800 \mathrm{rpm}$ to $1000 \mathrm{rpm}$ and feed rate of $20 \mathrm{~mm} / \mathrm{min}-40 \mathrm{~mm} / \mathrm{min}$ is used for the investigation. Maximum joint strength of $78.6 \%$ of aluminium base metal is achieved. Rotation speed of $800 \mathrm{rpm}$ and feed rate of 20 $\mathrm{mm} / \mathrm{min}$ are recognised as optimum parameters. Better joint strength is obtained because of formation of stable and hard inter metallic phase. S.D. Ji et al [15] performed the numerical simulation to investigate the material flow behaviour with rotation tool geometry. They concluded that material in the vicinity of thermos-mechanically affected zone flows downward and material near the tool flows upward when the right screw rotational tool rotates clockwise. Concentric circle flute shoulder shows the higher material flow velocity than the inner concave flute shoulder. Choosing the reasonable shoulder and pin geometry is important to avoid the root defects in weldments. Hasan et al [16] used worn and unworn tool geometries to compare the material flow in friction stir welding of AA7020. Hybrid mesh is used for achieving the good results, it is observed that mechanically affected zone with worn tool is about $2.5 \mathrm{~mm}$ smaller than unworn tool. Weld quality gets affected in worn tool due to weld penetration don't reach till bottom. Dawood et al [17] studied the effect of small tool pin profiles on mechanical properties and microstructure of AA 6061 joint made by FSW process. Threaded taper cylindrical, square and triangular profiles of tool are used for study. This study reveals that triangular shape tool profile gives the better mechanical and metallurgical weld properties than other two profiles. Square tool profile gives the lowest tensile strength and microhardness. Narrow heat affected zone is obtained with small pin profile and shoulder diameter with sufficient softening. The fracture mode for triangular specimen is observed as ductile while fracture mode for other two is brittle. M. Koilraj et al [18] optimized the process parameters during FSW of AA 2219 and AA5083. The parameters taken into consideration are rotation speed, traverse speed, ratio of tool shoulder diameter and pin diameter and tool geometry. Tensile strength is used as the criterion for optimization. They concluded that the rotation speed of $700 \mathrm{rpm}$, traverse speed of $15 \mathrm{~mm} / \mathrm{min}$ and shoulder to pin diameter ration of 3 are optimum parameters. Overall contribution of $\mathrm{D} / \mathrm{d}$ ratio is $60 \%$.

Fu et al [19] observed tensile strength improvement by reduction in Width of Heat affected zone (HAZ) in UFSW. They studied the temperature distribution and mechanical properties of AA 7050. Joints with best mechanical properties are observed in hot water UFSW. Heat affected zones shows the lowest value of microhardness in entire weld joint. H.J. Liu et al [20] studied the effect of rotation speed of $800 \mathrm{rpm}$ and various traverse speeds of 50 to 200 $\mathrm{mm} / \mathrm{min}$ on microstructure and mechanical properties of AA2219. They found that hardness value of joint has decreased with the increase in traverse speed of tool. Increase in traverse speed causes the deterioration of precipitate formed in heat affected zone and thermomechanically affected zone. Tensile strength increased with increase in welding speed but at speed of $200 \mathrm{~mm} / \mathrm{min}$ grove defect occurred which resulted in decrease in tensile strength. Huijie Zhang et al [21] choose the tensile strength as criterion for optimization of heat-treatable Aluminum alloy joints made by UFSW. Mathematical model is developed for optimization of welding parameters. Tensile strength obtained in UFSW is found to be $6 \%$ higher than that of FSW joint. Rotation speed and welding speed are identified as the predominant process parameters indicated by variance analysis. H.J. Zhang et al [22] investigated the effect of rotation speed on microstructure and mechanical properties of AA2216-T6 joint. Increase in dislocation 
density with increase in rotation speed is observed which leads to gradual increase in hardness. When the Rotation speed increased from 600 to $800 \mathrm{rpm}$ tensile strength is found to be increased first and then constant. Fracture in stir zone is observed for joints welded at low rotation speed. Hardness increase with increase in rotation speed causes the cracks to move in heat affected zone or thermomechanically affected zone from stir zone. Jie et al [23] carried out the mechanical property study to improve the tensile strength of UFSW joint when compared to FSW joint. The tensile strength of joint in case of air cooling is $324 \mathrm{MPa}$ wehile in case of water cooling it increased to 341 MPa. Fratini et al [24] studied the thermal cycles through numerical analysis. They concluded that simulation results of temperature histories in UFSW that water cooling results in thermal flow reduction near tool. This reduction in thermal flow causes the improvement in mechanical properties of welded joints. Hui-jie ZHANG et al [25] performed the thermal modelling of high strength aluminium alloy. They concluded that the peak temperature during the UFSW are less than the FSW. Thermal cycles are also found to be shrinked and more controlled than the FSW. From the above literature it is clear that properties of the welded joints made by FSW and UFSW have significant differences and process parameter selection plays the major role in determining quality of welding. It is observed from literature that very less work is available comparative study of FSW and UFSW of AA6063 though it has significant applications. In this paper an attempt is made to compare FSW and UFSW processes based on some important input parameters like rotational speed of tool, feed rate of tool and plunge pressure. Thermal and material flow histories are taken as results for comparison.

\section{Experimentation}

Experiments were performed on FSW-3T-NC machine tool. The system is controlled with two motors only, namely spindle motor and feed motor. These motors are linked to drive controllers. The spindle motor is rated at 22 $\mathrm{kW}$ and the feed bed motor is rated at $1.5 \mathrm{~kW}$. Both these motors use mechanical gearboxes to increase the torque on the output shaft. The main spindle motor provides the spindle rotation while the feed bed motor supplies power to all the three axis movements of the bed. The various axes of the bed namely X, Y and Z are engaged with $24 \mathrm{~V}$ electromagnetic clutches. Limit switches and emergency stop buttons are also linked to the PC with the PCI boards.

Aluminium Alloy 6063-T6 plates with dimensions of $250 \mathrm{~mm} \times 120 \mathrm{~mm} \times 6 \mathrm{~mm}$ are used as the work-material in the present work. The chemical composition of AA6063 is given in table 1 . The non-consumable conical tool used during the process is made of high speed steel. The conical tool has $19 \mathrm{~mm}$ diameter shoulder, top and bottom diameters of pin as $6 \mathrm{~mm}$ and $3 \mathrm{~mm}$ respectively and pin length of 5.8mm. All the experiments are carried out at 1 tilt angle of tool. Peak temperatures are measured by embedding $\mathrm{k}$ type thermocouples at a location $1 \mathrm{~mm}$ from the top of pin in leading direction. Rotation speed of 1100 $\mathrm{rpm}, 1200 \mathrm{rpm}$ and $1300 \mathrm{rpm}$ are used for experimentation. Feed rates used are $22 \mathrm{~mm} / \mathrm{min}, 44 \mathrm{~mm} / \mathrm{min}$ and 66 $\mathrm{mm} / \mathrm{min}$. Plunge pressures of $15 \mathrm{MPa}, 17 \mathrm{MPa}$ and $19 \mathrm{MPa}$ are applied on tool during experiments. Experiments are performed at suitable combinations of rotation speed, feed rate and plunge pressure. Three experiments are performed for each combination of parameters. Average values of temperatures are considered for the analys is.

Table 1. Chemical composition of AA6063-T6 (wt.\%)

\begin{tabular}{|c|c|c|c|c|c|c|c|c|c|c|}
\hline Element & $\mathrm{Al}$ & $\mathrm{Cu}$ & $\mathrm{Mg}$ & $\mathrm{Mn}$ & $\mathrm{Fe}$ & $\mathrm{Si}$ & $\mathrm{Ti}$ & $\mathrm{Cr}$ & $\mathrm{Zn}$ & $\mathrm{Ni}$ \\
\hline AA6063 & 98.71 & 0.022 & 0.499 & 0.034 & 0.250 & 0.424 & 0.015 & 0.005 & 0.028 & 0.003 \\
\hline
\end{tabular}

Table 2. Specifications of the machine

\begin{tabular}{|l|l|}
\hline Element & Range \\
\hline Spindle motor & $22 \mathrm{Kw} / 440 \mathrm{~V}$ (AC Drive) \\
\hline Spindle speed & $\begin{array}{l}200 \text { to } 4000 \mathrm{rpm} \\
\text { (infinitely Variable) }\end{array}$ \\
\hline Z axis stroke (Auto) & $300 \mathrm{~mm}$ \\
\hline Z axis stroke (manual - hand wheel) & $25 \mathrm{~mm}$ \\
\hline Z axis thrust & $500(\mathrm{Min})-6000 \mathrm{kgf}$ (Max) \\
\hline Z axis rapid traverse & $2000 \mathrm{~mm} / \mathrm{min}$ \\
\hline X axis stroke - (Auto) & $600 \mathrm{~mm}$ \\
\hline X axis Feed & 0 to $500 \mathrm{~mm} / \mathrm{min}$. \\
\hline$X$ axis thrust & $\begin{array}{l}250(\text { Min) }-2500 \mathrm{kgf} \text { (Max) } \\
\text { (Adjust able in steps of 50 kgf) }\end{array}$ \\
\hline Y axis stroke (manual - hand wheel) & $200 \mathrm{~mm}$ \\
\hline Table & $\begin{array}{l}600 \times 350 \mathrm{~mm} \\
\text { 'T' slot }-18 \times 3 \mathrm{~mm}\end{array}$ \\
\hline Spindle motor & Stark \\
\hline Z axes feed force feedback & Load cells for each axis provided \\
\hline
\end{tabular}




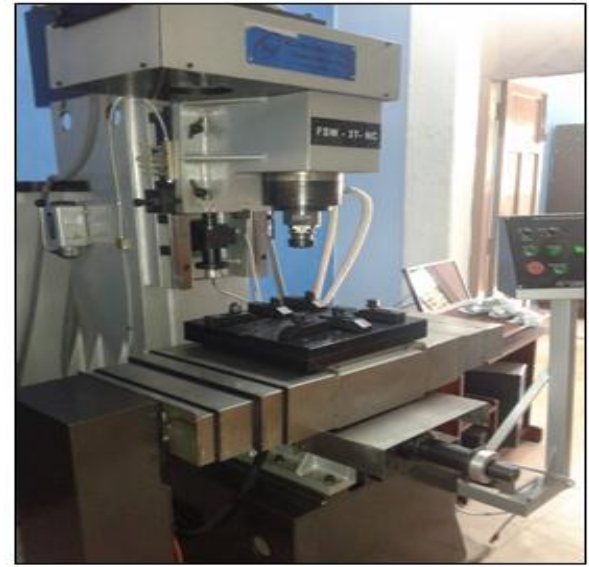

Figure 1. FSW Machine setup

\section{Modelling and Simulation}

In the present study, three-dimensional model is developed, Ansys FLUENT package is used for developing the model. The work piece is divided into the two parts during the simulation, Central part which has the shoulder of the tool is considered as liquid while the remaining part of the model is considered as solid. Momentum and thermal boundary conditions are given to the liquid part whereas only thermal boundary conditions are given to the solid part.

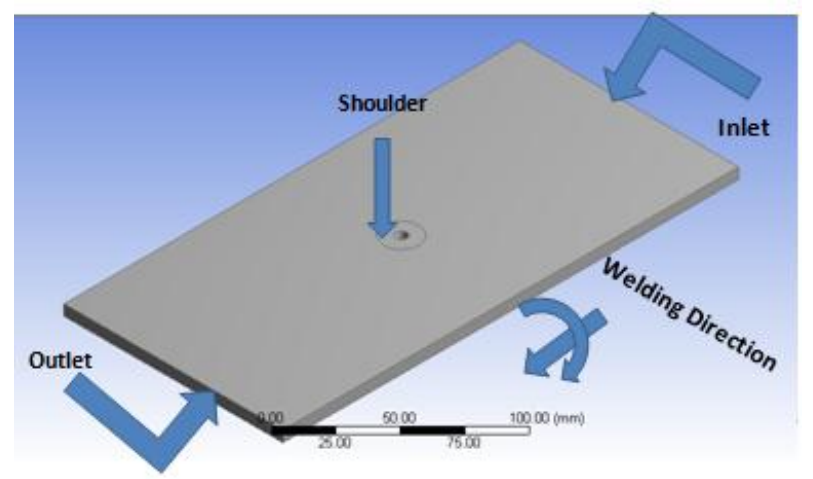

Figure 2. Model of FSW process

The flow of material is considered as the Non-Newtonian, incompressible and Visco-plastic. Heat generation rate is considered constant during the process except start and end position. Reduction in the convergence error and highly accurate nodal coordinates are obtained by considering the double precision option for modelling. Variation in the density is neglected according to bossiness's approximation.

Material properties such as Density, Specific heat, Thermal conductivity and Viscosity are used in present study. Material viscosity is taken as the function of temperature and strain rate, other properties are taken as constant values. UDF formulations are used for calculating the Material viscosity, Zener-Hollomon parameter and flow stress values. Material constants required during the calculations are provided in table No. 2.

$$
\begin{gathered}
\sigma_{f}=\frac{1}{\alpha} \sinh ^{-1}\left[\left(\frac{Z}{A}\right)^{\frac{1}{n}}\right] \\
Z=\varepsilon \exp \left(\frac{Q}{R t}\right) \\
\mu=\frac{\sigma_{f}}{3 \varepsilon}
\end{gathered}
$$

Where $A, \alpha$ and $n$ are material constants, $\mathrm{Z}$ is Zener Hollomon parameter, $\mathrm{Q}$ is activation energy, $\mathrm{R}$ is Universal gas constant, $\mathrm{t}$ is the Temperature, $\sigma \mathrm{f}$ is flow stress $\mu$ is viscosity, and $\varepsilon$ is strain rate.

Table 3. Material properties of AA6063 [26]

\begin{tabular}{|c|c|}
\hline Material Property & Value \\
\hline Density $\left(\rho_{0}\right)$ & $2700 \mathrm{~kg} / \mathrm{m}^{3}$ \\
\hline Thermal conductivity & $200 \mathrm{~W} / \mathrm{mK}$ \\
\hline Material constant $(\mathrm{A})$ & $1.4506 \times 10^{14} \mathrm{~s}^{-1}$ \\
\hline Material constant $(\alpha)$ & $0.0164 \mathrm{MPa}^{-1}$ \\
\hline Material constant $(\mathrm{n})$ & 9.0439 \\
\hline Activation energy $(\mathrm{Q})$ & $181.8906 \mathrm{KJ} / \mathrm{Mol}$ \\
\hline
\end{tabular}

Metal material is assumed as the fluid during the simulation process and different boundary conditions are applied. Among all the boundary conditions partial stickslip condition is observed to give the good results. For the reference, temperature values for stick, slip and partial stick-slip boundary condition are given below in table 4 . The values of momentum and thermal boundary conditions are calculated for different processing conditions. The shear yield stress of material is calculated from von-misis critiria as

$$
\tau_{\text {yeild }}=\frac{\sigma_{y e i l d}}{\sqrt{3}}
$$

Table 4. Temperature values for stick, slip and partial stick-slip condition

\begin{tabular}{|c|c|c|c|c|}
\hline \multirow{2}{*}{$\begin{array}{c}\text { Rotational speed of tool } \\
(\mathrm{rpm})\end{array}$} & \multicolumn{3}{|c|}{ FSW Process } & \\
\cline { 2 - 5 } & $\begin{array}{c}\text { Temperature } \\
(\mathrm{k}) \\
(\text { Experimental) }\end{array}$ & $\begin{array}{c}\text { Temperature (k) } \\
\text { (Stick boundary condition) }\end{array}$ & $\begin{array}{c}\text { Temperature (k) } \\
\text { (Partial stick-slip boundary } \\
\text { condition) }\end{array}$ & $\begin{array}{c}\text { Temperature (k) } \\
\text { (Slip boundary } \\
\text { condition) }\end{array}$ \\
\hline 1100 & 390 & 448 & 377 & 308 \\
\hline 1200 & 394 & 456 & 388 & 312 \\
\hline 1300 & 393 & 463 & 399 & 315 \\
\hline
\end{tabular}




\subsection{Calculation of Friction and Slip Coefficient}

The values of the friction and slip coefficient are the important parameters to be considered while simulating the FSW process. Their values affect the both momentum as well as thermal boundary conditions and thereby the accuracy of the numerical model. The values of the coefficients once calculated considered as the constant for the entire case.

The values of friction coefficient $\left(\mu_{\mathrm{f}}\right)$ and slip coefficient $(\delta)$ are calculated with the help of following equations [27]:

$$
\begin{gathered}
\mu_{\mathrm{f}}=0.5 \times \exp (-\delta \omega r) \\
\delta=0.31 \times \exp (\omega r / 1.87)-0.026
\end{gathered}
$$

Where $\mu_{f}$ is the friction coefficient, $\delta$ slip coefficient, $\omega$ Rotational speed of the tool, $r$ length between the tool axis and elemental area.

\subsection{Shear and Heat Equations}

The values of the contact shear stress between the tool and work piece interface are calculated from the shear equations. Since tool profile is conical, consideration of the cone angle of the tool is very important in shearcalculation of tool pin wall and work piece interface [11].

1. Heat generation at the tool shoulder, tool pin bottom and work piece interface:

$$
\mathrm{q}_{0}=\beta_{2}\left[\delta \tau_{\mathrm{y}}+(1-\delta) \mu_{\mathrm{f}} \mathrm{p}_{0}\right] \mathrm{r} \omega
$$

2. Heat generation at tool pin side and work piece interface:

$$
\mathrm{q}_{1}=\beta_{2}\left[\delta \tau_{\mathrm{y}}+(1-\delta) \mu_{\mathrm{f}} \mathrm{p}_{0} \sin \xi\right] \mathrm{r} \omega
$$

Where $\beta_{2}$ is the thermal conversion efficiency at tool work piece interface.

Thermal conductivities of tool and work piece material are different, therefore some portion of amount of heat generated at tool work piece interface would transfer to the tool also. The portion of heat transfer to the tool $(\lambda)$ is function of heat capacity, density and thermal conductivity of tool and work piece material and estimated as:

$$
\lambda=\frac{\sqrt{\left(k \rho c_{p}\right)_{w}}}{\sqrt{\left(k \rho c_{p}\right)_{w}}+\sqrt{\left(k \rho c_{p}\right)_{T}}}
$$

Convection and radiation heat transfer coefficients are used at top surface of work piece as follows:

$$
-k{\frac{\partial T}{\partial y_{\text {top }}}}=\sigma \varepsilon\left(T^{4}-T_{a}^{4}\right)+h_{t}\left(T-T_{a}\right)
$$

At the bottom surface convective heat boundary is considered

$$
k{\frac{\partial T}{\partial y_{\text {bottom }}}}=h_{b}\left(T-T_{a}\right)
$$

Values of $h_{t}$ and $h_{b}$ are taken as $5 \mathrm{~W} / \mathrm{m}^{2} \mathrm{k}$ for FSW and for UWFSW values are calculated as $1260 \mathrm{~W} / \mathrm{m}^{2} \mathrm{k}$ and $1320 \mathrm{~W} / \mathrm{m}^{2} \mathrm{k}$ respectively [28].

For the steady, incompressible and single phase flow of
FSW material the continuity equation is given as:

$$
\frac{\partial u}{\partial x}+\frac{\partial v}{\partial y}+\frac{\partial w}{\partial z}=0
$$

Where $\mathrm{u}, \mathrm{v}, \mathrm{w}$ are the material flow velocity along $\mathrm{x}, \mathrm{y}$ and $\mathrm{z}$ axis respectively.

Conservation of momentum equation in the index form can be written as

$$
\rho\left(u \frac{\partial u}{\partial x}+v \frac{\partial u}{\partial y}+w \frac{\partial u}{\partial z}\right)=-\frac{\partial p}{\partial x}+\mu\left(\frac{\delta^{2} u}{\delta x^{2}}+\frac{\delta^{2} u}{\delta y^{2}}+\frac{\delta^{2} u}{\delta z^{2}}\right)
$$

$$
\begin{gathered}
\rho\left(u \frac{\partial v}{\partial x}+v \frac{\partial v}{\partial y}+w \frac{\partial v}{\partial z}\right)=-\frac{\partial p}{\partial y}+\mu\left(\frac{\delta^{2} v}{\delta x^{2}}+\frac{\delta^{2} v}{\delta y^{2}}+\frac{\delta^{2} v}{\delta z^{2}}\right) \\
\rho\left(u \frac{\partial w}{\partial x}+v \frac{\partial w}{\partial y}+w \frac{\partial w}{\partial z}\right)=-\frac{\partial p}{\partial z}+\mu\left(\frac{\delta^{2} w}{\delta x^{2}}+\frac{\delta^{2} w}{\delta y^{2}}+\frac{\delta^{2} w}{\delta z^{2}}\right)
\end{gathered}
$$

Energy equation can be written as:

$$
\begin{gathered}
\rho c_{p}\left(u \frac{\partial T}{\partial x}+v \frac{\partial T}{\partial y}+w \frac{\partial T}{\partial z}\right)=\frac{\partial}{\partial x}\left(k \frac{\partial T}{\partial x}\right)+\frac{\partial}{\partial y}\left(k \frac{\partial T}{\partial y}\right)+\frac{\partial}{\partial z}(k \\
\left.\frac{\partial}{\partial z}\right)+S_{v}
\end{gathered}
$$

where $S_{v}$ is the viscous dissipation source, kis the thermal conductivity, $c_{p}$ is the specific heat at constant pressure, $\mu$ is the viscosity, $\rho$ is the density and $\mathrm{p}$ is the pressure.

$$
S_{v}=\beta \mu \dot{\varepsilon}^{2}
$$

Where $\beta$ is fraction which converted into heat.

$$
\dot{\varepsilon}=\sqrt{\frac{2}{3}\left[\begin{array}{c}
\left(\frac{\partial u}{\partial x}\right)^{2}+\left(\frac{\partial v}{\partial y}\right)^{2}+\left(\frac{\partial w}{\partial z}\right)^{2}+\frac{1}{2}\left(\frac{\partial u}{\partial y}+\frac{\partial v}{\partial x}\right)^{2} \\
+\frac{1}{2}\left(\frac{\partial u}{\partial z}+\frac{\partial w}{\partial x}\right)^{2}+\frac{1}{2}\left(\frac{\partial v}{\partial z}+\frac{\partial w}{\partial y}\right)^{2}
\end{array}\right]}
$$

In order to carry out numerical analysis models are created for both FSW and UFSW. Numerical simulation is conducted in CFD software FLUENT. Semi-Implic it Method for Pressure Linked Equations (SIMPLE) algorithm is used for the coupled temperature and velocity field calculations. Geometry created has the same dimensions as workpiece used in experimental work. The magnitude of tool dimensions and tilt angle used for experiment are considered for simulation also. Finer mesh is provided near the tool in order to capture the results accurately. Flow of visco-plastic material during processes is assumed as laminar. Appropriate values of momentum boundary conditions are calculated and given as input in both the models. The only difference in both models is of heat transfer coefficient (HTC) values of working environment. HTC values are calculated for individual model and given as thermal boundary conditions. Final solutions are taken only after the convergence criterion fulfilment. Rotational speeds used have magnitudes of $1100 \mathrm{rpm}, 1200 \mathrm{rpm}$ and $1300 \mathrm{rpm}$ in both FSW as well as UFSW. Rotating tool travels in longitudinal direction with $22 \mathrm{~mm} / \mathrm{min}, 44 \mathrm{~mm} / \mathrm{min}$ and $66 \mathrm{~mm} / \mathrm{min}$ feed rate. The values of the Plunge pressure are taken as $15 \mathrm{MPa}, 17 \mathrm{MPa}$ and $19 \mathrm{Mpa}$ in both the cases. 


\section{Result and Discussion}

\subsection{Validation of Model}

Models are validated by observing magnitudes of static temperature in experiment and simulation work for both the processes. Static temperatures were measured in longitudinal direction at a distance of $1 \mathrm{~mm}$ from the upper end of conical tool. Validation is performed at constant feed rate and plunge pressure of $22 \mathrm{~mm} / \mathrm{min}$ and $17 \mathrm{MPa}$ respectively. Rotational speeds of $1100 \mathrm{rpm}, 1200 \mathrm{rpm}$ and $1300 \mathrm{rpm}$ are considered. The experimental and numerical values of temperature along with percentage error for both FSW and UFSW are given in table 5. Temperature distribution profiles for FSW and UFSW are shown in fig. 3 and fig. 4 respectively. Peak temperatures generated during the FSW and UFSW are plotted in fig.5.

Table 5. Experimental and numerical values of temperature and percentage error

\begin{tabular}{|c|c|c|c|c|c|c|}
\hline \multirow[b]{2}{*}{ Rpm } & \multicolumn{2}{|r|}{ FSW } & \multirow{2}{*}{$\begin{array}{l}\% \text { Error } \\
\text { in FSW }\end{array}$} & \multicolumn{2}{|c|}{ UFSW } & \multirow{2}{*}{$\begin{array}{l}\% \text { Error in } \\
\text { UFSW }\end{array}$} \\
\hline & $\begin{array}{c}\text { Experimental } \\
\text { Temperature (k) }\end{array}$ & Simulation Temperature (k) & & $\begin{array}{c}\text { Experiment } \\
\text { Temperature }(\mathrm{k})\end{array}$ & $\begin{array}{c}\text { Simulation } \\
\text { Temperature (k) }\end{array}$ & \\
\hline 1100 & 390 & 377 & 3.33 & 362 & 373 & 3.03 \\
\hline 1200 & 394 & 388 & 1.52 & 361 & 384 & 6.37 \\
\hline 1300 & 393 & 399 & 1.52 & 360 & 393 & 9.16 \\
\hline
\end{tabular}

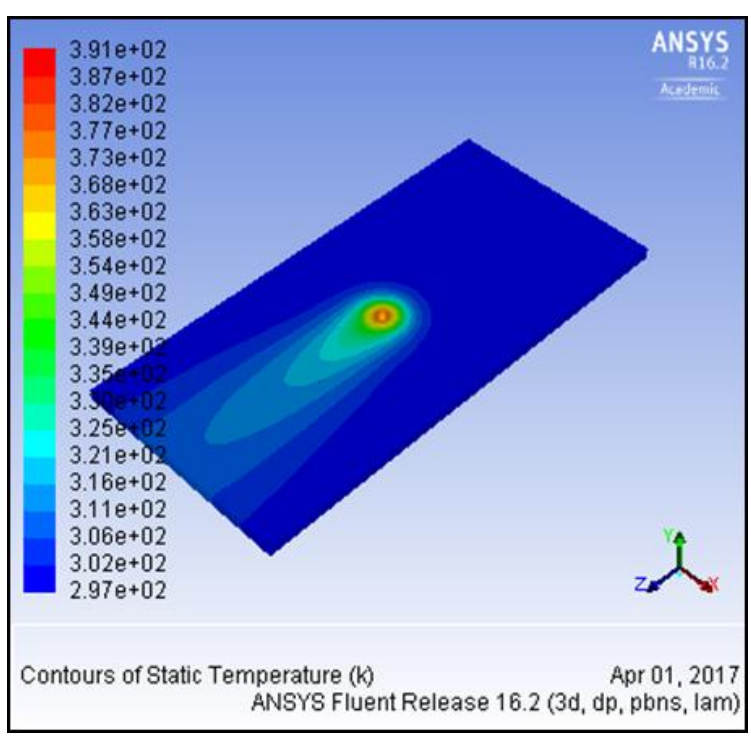

(a)

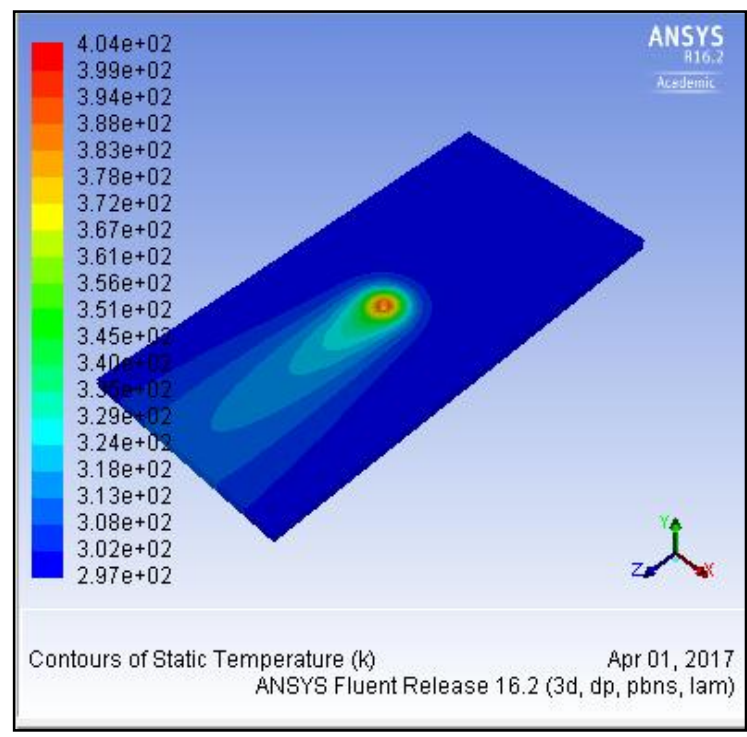

(b)

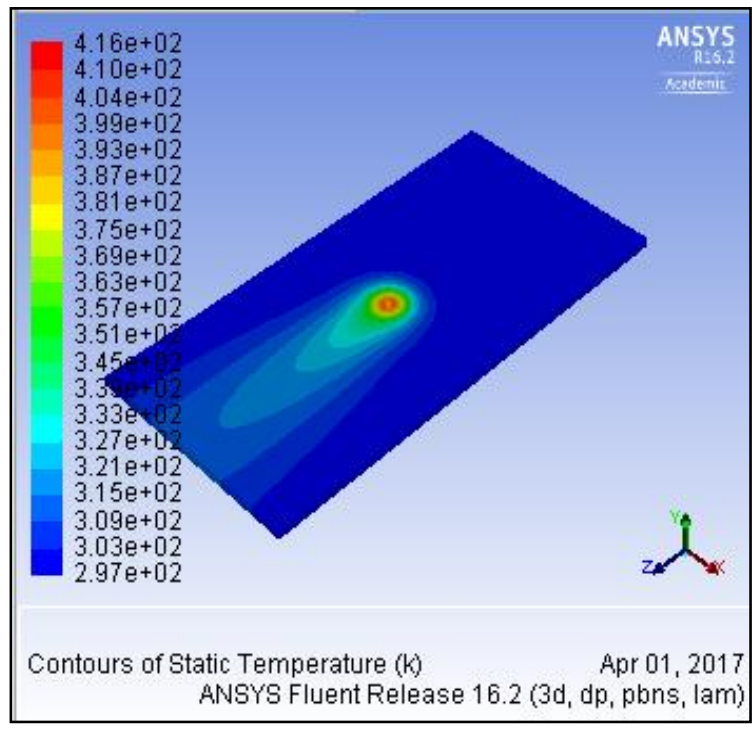

(c)

Figure 3. Temperature profiles in FSW at feed rate of $22 \mathrm{~mm} / \mathrm{min}$, plunge pressure of $17 \mathrm{Mpa}$ and rotation speed of (a) $1100 \mathrm{rpm}$ (b) $1200 \mathrm{rpm}$ (c) $1300 \mathrm{rpm}$ 


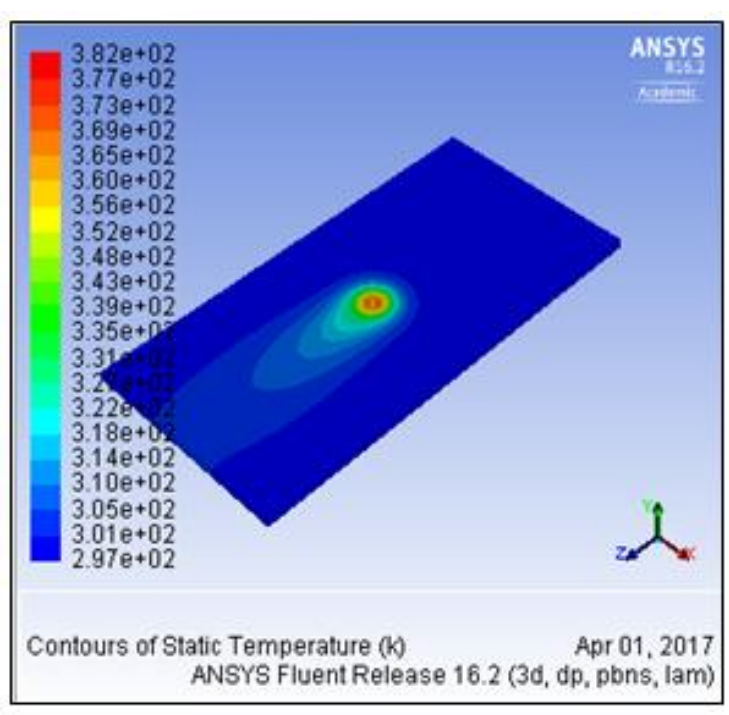

(a)

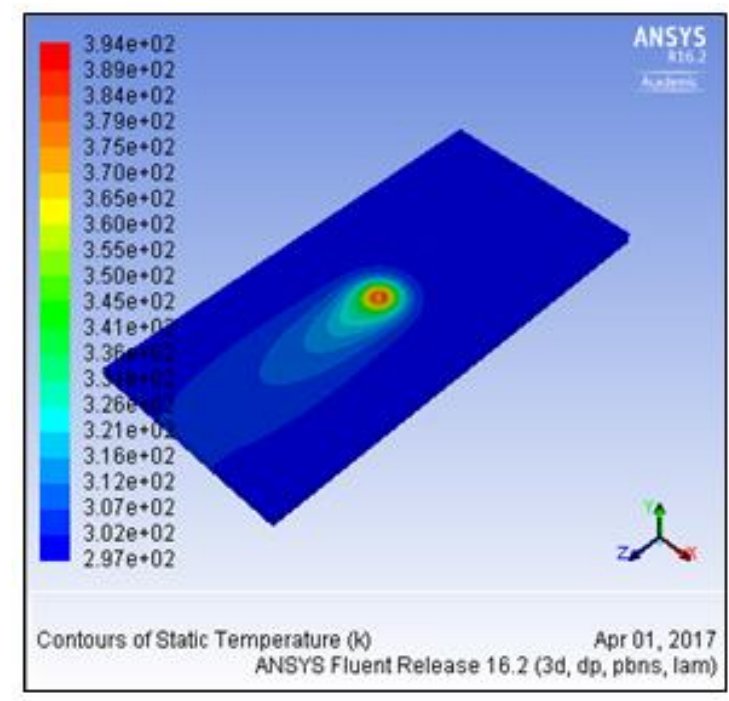

(b)

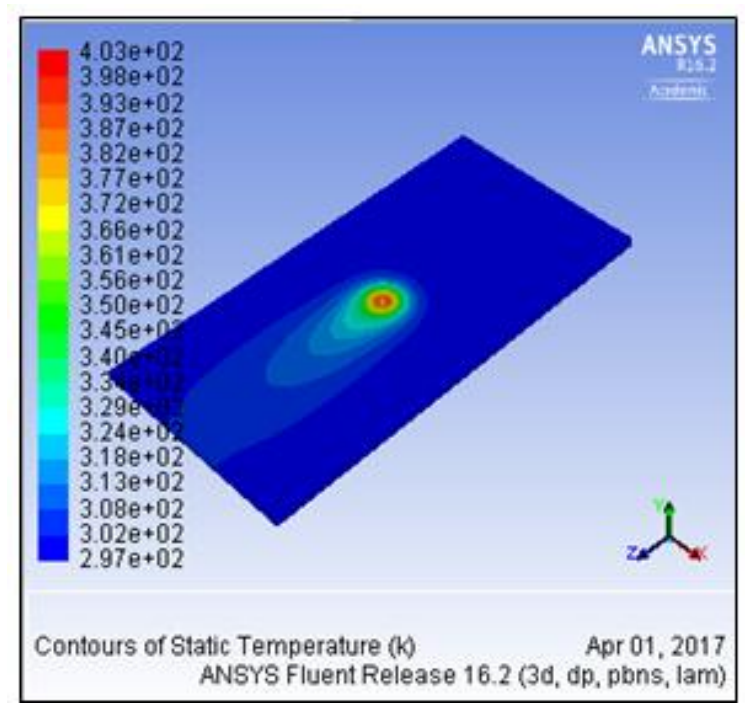

(c)

Figure 4. Temperature profiles in UFSW at feed rate of $22 \mathrm{~mm} / \mathrm{min}$, plunge pressure of $17 \mathrm{Mpa}$ and rotation speed of (a) $1100 \mathrm{rpm}$ (b) $1200 \mathrm{rpm}$ (c) $1300 \mathrm{rpm}$

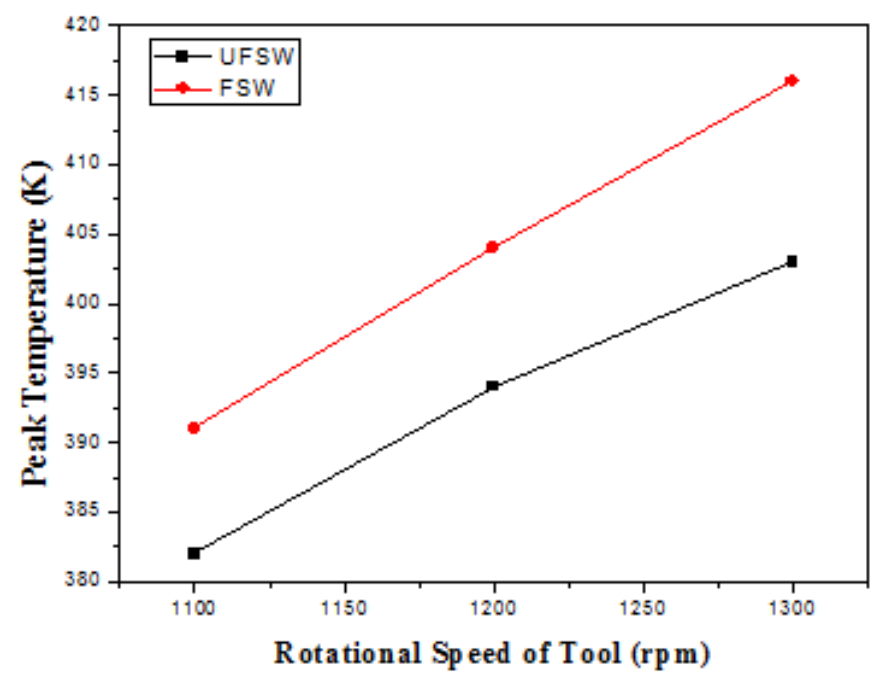

Figure 5. Rotational Speed Vs Peak Temperature 


\subsection{Effect of Process Parameter on Temperature Distribution}

To study the effect of tool rotation speed, feed rate and plunge pressure on temperature distribution multiple models are generated and solved at different conditions. The variation of temperature with respect to rotation speed is derived by keeping feed rate and plunge pressure constant. Effect of process parameters on the temperature distribution is shown in fig.6.

In fig.6(a), when feed rate and plunge pressure is kept constant temperature increases with increase in rotation speed. When the rotation speed is changed from $1100 \mathrm{rpm}$ to $1300 \mathrm{rpm}$ at constant feed rate of $22 \mathrm{~mm} / \mathrm{min}$ and constant plunge pressure of $15 \mathrm{MPa}$, peak value of temperature increases by $5 \%$. Models with plunge pressure of $17 \mathrm{Mpa}$ and $19 \mathrm{MPa}$ as shown in fig.6(b) and (c) follows the same trend at feed rate of $22 \mathrm{~mm} / \mathrm{min}$, increase in temperature is $6 \%$ approximately in both cases. Similarly, when rotation speed is varied at high feed rates increasing trend is observed in peak temperature. Now to investigate the effect of feed rate on peak temperature generated during the process rotation speed of tool and plunge pressure on tool are kept constant at $1100 \mathrm{rpm}$ and $15 \mathrm{MPa}$ respectively and feed rate varied as $22 \mathrm{~mm} / \mathrm{min}, 44 \mathrm{~mm} / \mathrm{min}$ and 66 $\mathrm{mm} / \mathrm{min}$. Decrease in peak temperature by $10.7 \%$ is noted when feed rate changed from $22 \mathrm{~mm} / \mathrm{min}$ to $66 \mathrm{~mm} / \mathrm{min}$ at constant rotation speed of $1100 \mathrm{rpm}$ and plunge pressure of $15 \mathrm{MPa}$. Models with plunge pressure of $17 \mathrm{Mpa}$ and 19 $\mathrm{MPa}$ as shown in fig.6(b) and (c) follows the same trend at rotation speed of $1100 \mathrm{rpm}$, decrease in temperature is approximately $10 \%$ in both the cases. Feed rate when varied at high rotation speed shows the decreasing trend of temperature.

Temperature distribution with respect to process parameters of UFSW process is shown in fig.7. Effect of process parameters in UFSW are studied in the same manner as in FSW. When the rotation speed varied from $1100 \mathrm{rpm}$ to $1300 \mathrm{rpm}$ at constant feed rate of $22 \mathrm{~mm} / \mathrm{min}$ and plunge pressure of $15 \mathrm{MPa}$ peak temperature is increased by $2.3 \%$ fig. 7(a) highlights the same. As shown in fig. 7 (b) and (c) at the Plunge pressure of $17 \mathrm{MPa}$ and $19 \mathrm{MPa}$ and the feed rate of $22 \mathrm{~mm} / \mathrm{min}$ approximately $5 \%$ increase in temperature is observed. Similar type of increasing trend in peak temperature is observed when rotation speed is varied at high feed rates.

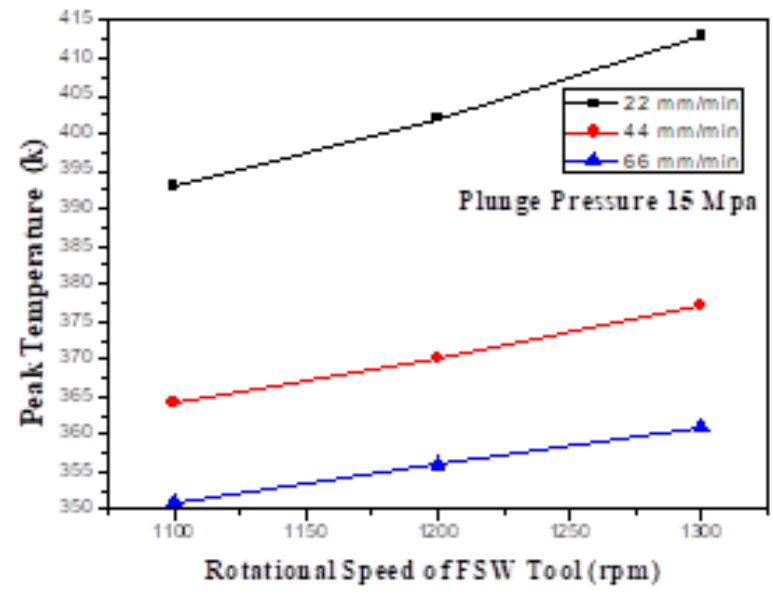

(a)

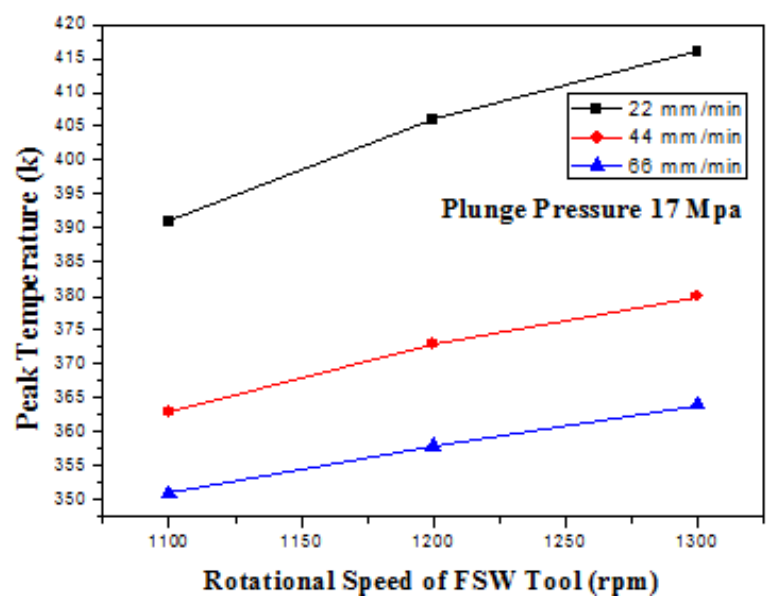

(b)

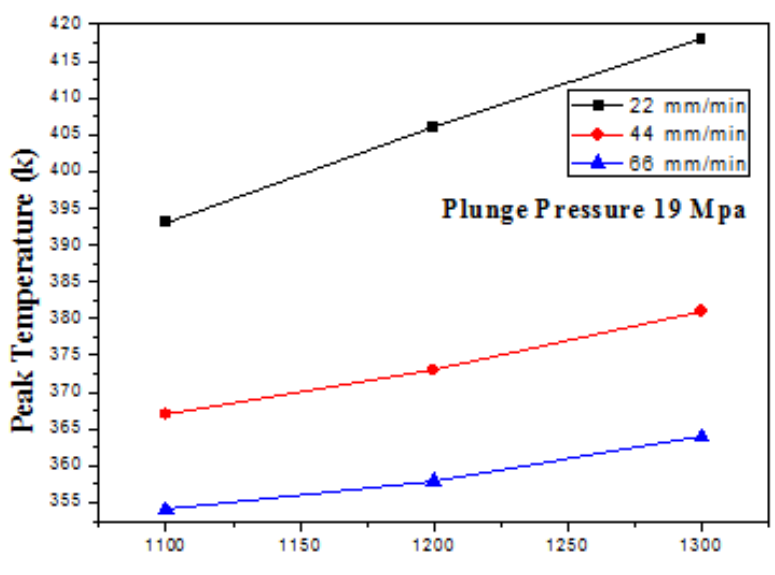

(c)

Figure 6. Temperature Variation in FSW with rotation of tool at plunge pressure of (a) $15 \mathrm{Mpa}$ (b) $17 \mathrm{Mpa}$ (c) $19 \mathrm{Mp}$ 
To carry out the analysis for feed rate, rotation speed of tool and plunge pressure on tool are kept constant. Decrease in temperature is noted when feed rate is increased. Rotation speed is kept constant at $1100 \mathrm{rpm}$ and plunge pressure at $15 \mathrm{MPa}$, feed rate when changed from 22 $\mathrm{mm} / \mathrm{min}$ to $66 \mathrm{~mm} / \mathrm{min}$, decrease in temperature by $8.3 \%$ is observed. Decrease in Peak temperature by $8.7 \%$ is observed at plunge pressure of $17 \mathrm{MPa}$ and $19 \mathrm{MPa}$ at rotation speed of $1100 \mathrm{rpm}$ with change in feed rate as shown in fig. 7 (b) and (c). Feed rate when varied at high rotation speed shows the decreasing trend of temperature.

The rate of plastic deformation of material increases with increase in rotation speed, which causes increase in heat generation and peak temperature during both the processes. Increase in peak temperature is about 5\%-6\% in FSW while in UFSW rate of increase is $2.3 \%-5 \%$. The rate of increase in peak temperature is more in case of FSW than the UFSW. Temperature profiles are observed to be shrinked in UFSW when compared with temperature profiles of FSW at same conditions of input parameters. Increase in the feed rate while keeping Rpm and plunge pressure constant causes the reduction in peak temperature, both FSW and UFSW follows same trend with lesser percentage reduction in UFSW. Percentage reduction in peak temperature is about $10 \%-10.7 \%$ in case of FSW where as for UFSW same is $8 \%-8.7 \%$. The above mentioned differences are observed in two processes because the different heat transfer coefficient values of air and Water. Water with high heat transfer coefficient draws the more amount of heat from work material than air can in the same time. Increase in feed rate leads to decrease in time of contact between the tool and material which causes less heat generation and consequently decrease in peak temperature. The main purpose of plunge pressure is forging the stirred material back side of tool during the process, in addition to this it also affects the contact shear stress and heat generation rate, which leads to the slight increase in temperature with increase in plunge pressure.

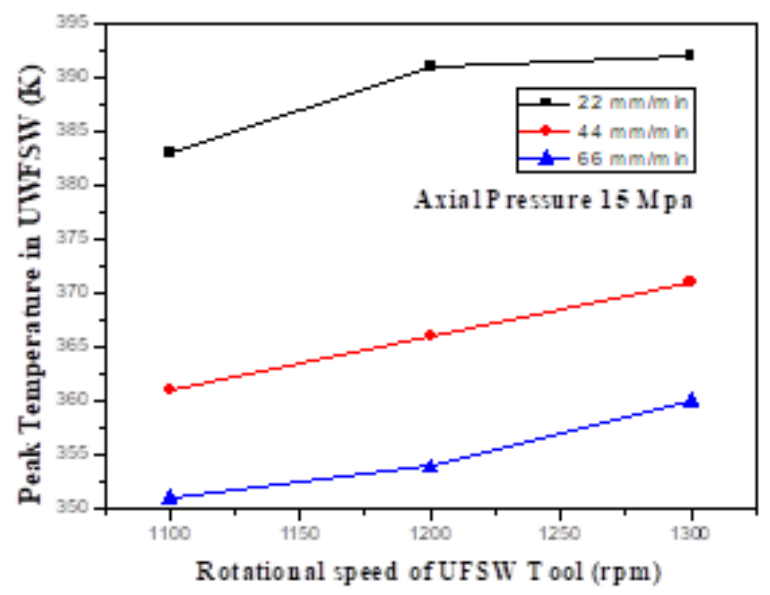

(a)

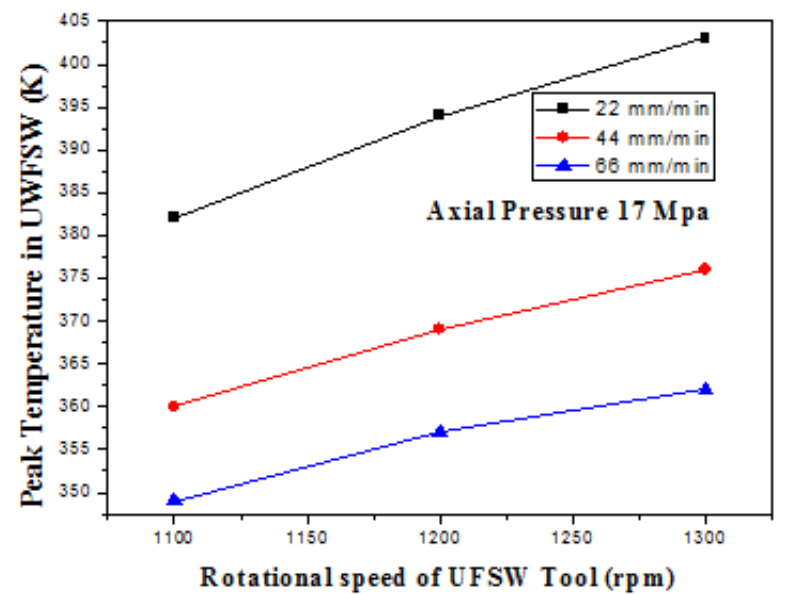

(b)

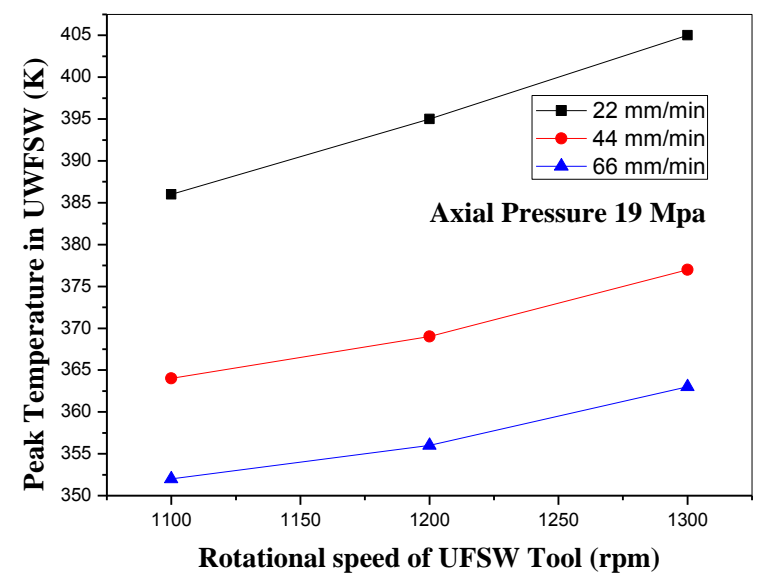

(c)

Figure 7. Temperature Variation in UFSW with rotation of tool at plunge pressure of (a) $15 \mathrm{Mpa}$ (b) $17 \mathrm{Mpa}$ (c) $19 \mathrm{Mpa}$

\subsection{Effect of Process Parameter on Material Flow Velocity}

Material flow velocity profiles are also plotted for both FSW and UFSW. The flow of material depends upon the type of contact occurring between tool and workpiece interface during the process. Partial stick-slip condition consideration combines the effect of stick and slip condition. Viscosity of material plays the major role in deciding contact condition between tool and workpiece. If stick condition has occurred during the process then with increase in rotational speed, material flow velocity will also increase because of sufficient heat generation due to plastic deformation. Material flow velocity profiles in FSW gives the quality of process in terms of distribution of material. Material flow patterns for FSW and UFSW are shown in fig. 8 and fig. 9 respectively. 
Fig. 8 and fig. 9 show the variation of material flow distribution at different rotation speed when feed rate is kept constant at $22 \mathrm{~mm} / \mathrm{min}$ and plunge pressure at $17 \mathrm{MPa}$ in FSW and UFSW respectively. Increase in material flow velocity by $5.93 \%$ is observed when rotation speed is changed from $1100 \mathrm{rpm}$ to $1200 \mathrm{rpm}$, fig. 8(a) and (b) shows the same. Rotation speed when changed from 1100 $\mathrm{rpm}$ to $1300 \mathrm{rpm}$ then increase in flow velocity is $8.6 \%$. In order to investigate the effect of feed rate on material flow

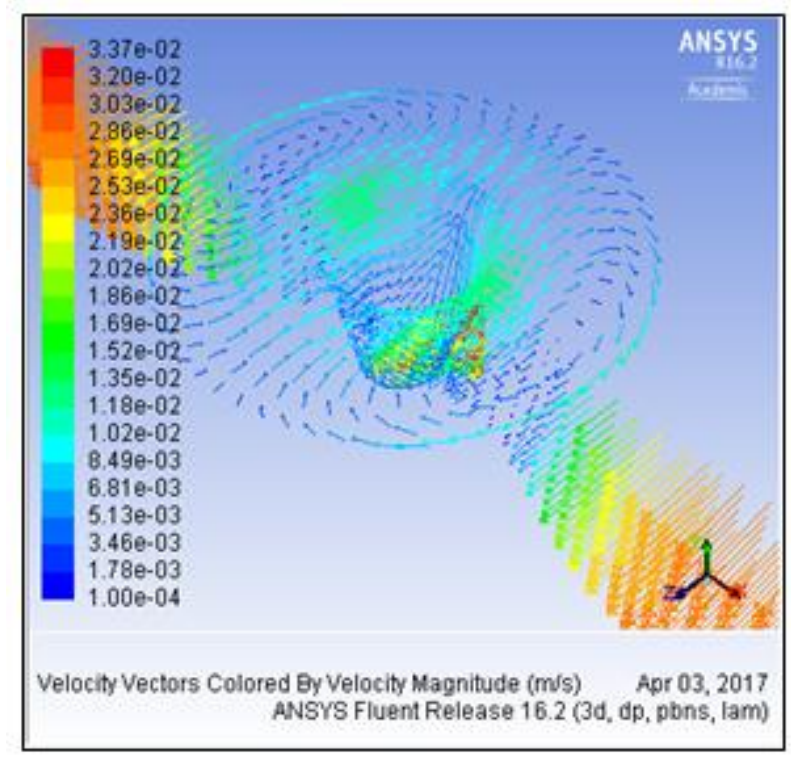

(a) velocity rotation speed of the tool and plunge pressure is kept constant. Feed rate when changed from $22 \mathrm{~mm} / \mathrm{min}$ to $44 \mathrm{~mm} / \mathrm{min}$ at rotation speed of $1100 \mathrm{rpm}$ and plunge pressure of $15 \mathrm{MPa}$, increase in material flow velocity by $60.95 \%$ is observed. Increase in material flow by $134.6 \%$ is obtained when the feed rate is changed from $22 \mathrm{~mm} / \mathrm{min}$ to $66 \mathrm{~mm} / \mathrm{min}$ by keeping other two parameters constant as previous. Graphs shown in fig. 10 supports the above discussion.

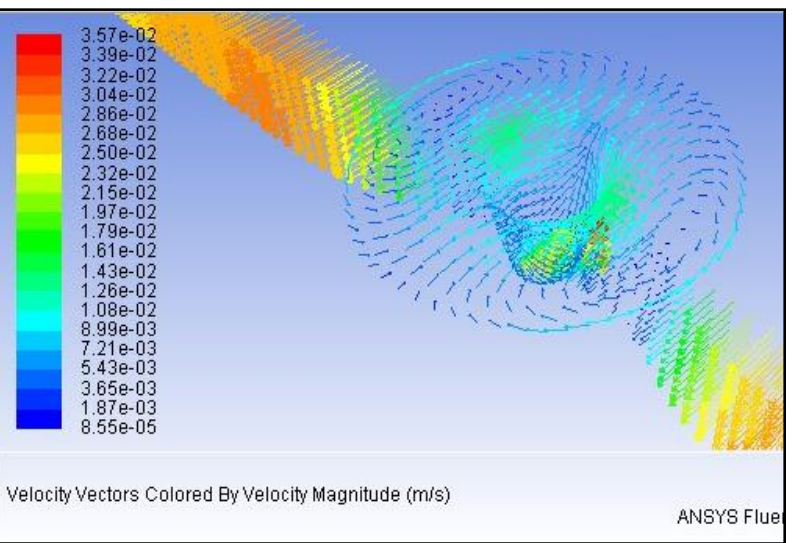

(b)

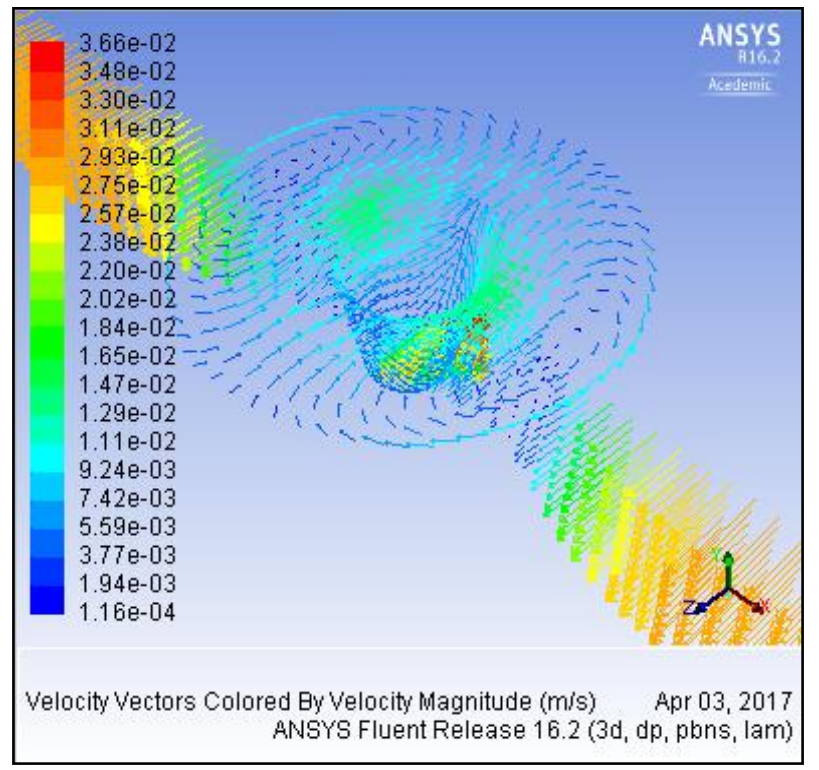

(c)

Figure 8. Material flow in FSW at feed rate of $22 \mathrm{~mm} / \mathrm{min}$, plunge pressure of 17 Mpa and rotation speed of (a) $1100 \mathrm{rpm}$ (b) $1200 \mathrm{rpm}$ (c) 1300 


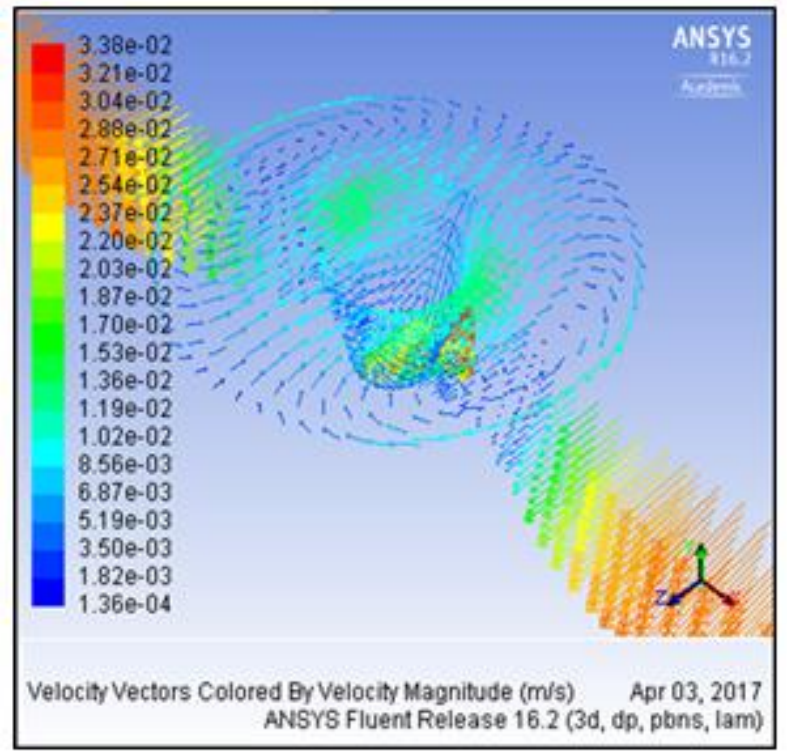

(a)

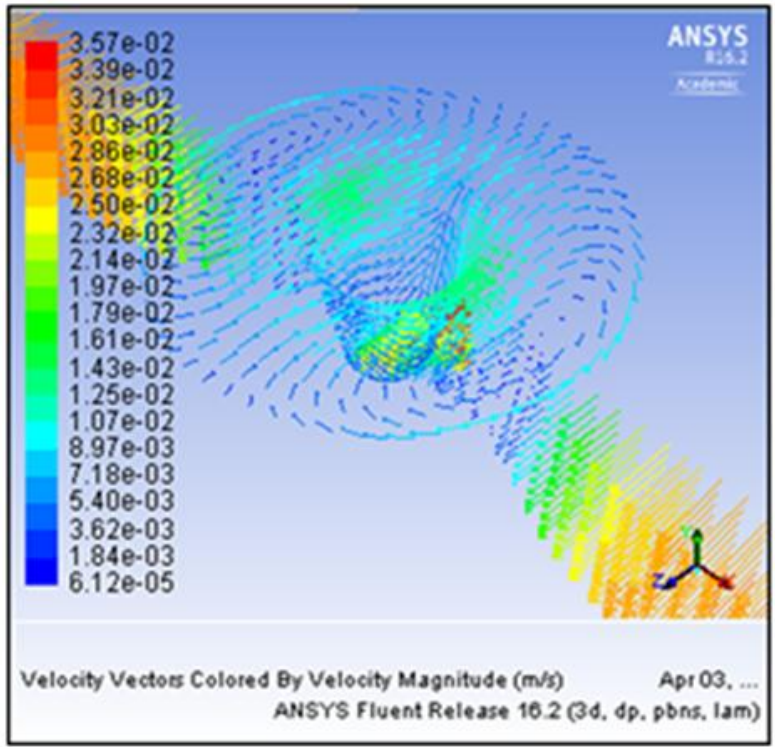

(b)

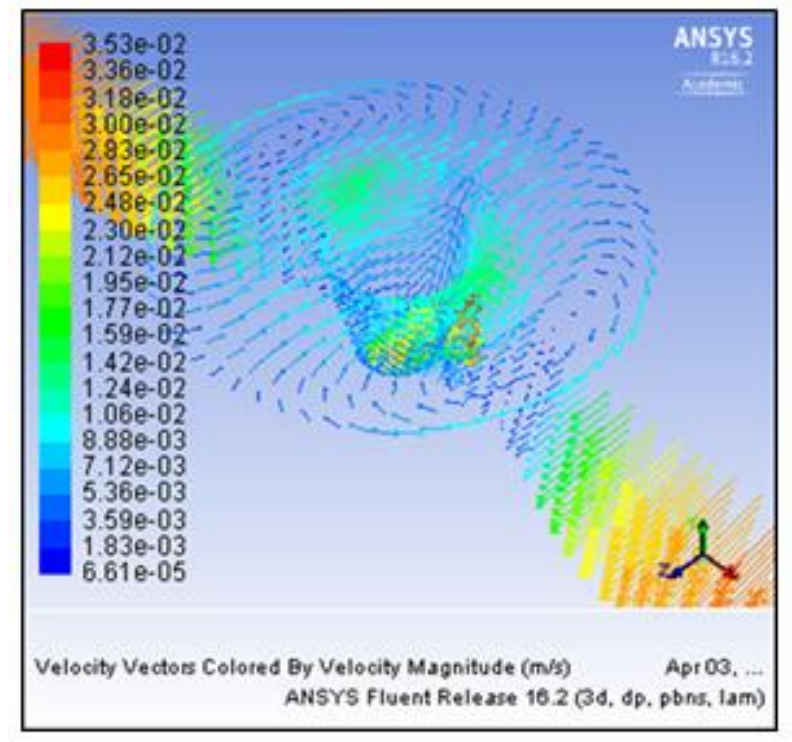

(c)

Figure 9. Material flow in UFSW at feed rate of $22 \mathrm{~mm} / \mathrm{min}$, plunge pressure of $17 \mathrm{Mpa}$ and rotation speed of (a) $1100 \mathrm{rpm}$ (b) $1200 \mathrm{rpm}$ (c) 1300

Fig. 9 highlights the changes are material flow velocity in UFSW with process parameters. Rotation speed when changed from $1100 \mathrm{rpm}$ to $1200 \mathrm{rpm}$ by keeping feed rate constant at $22 \mathrm{~mm} / \mathrm{min}$ and plunge pressure at $17 \mathrm{MPa}$, increase in flow rate by $5.62 \%$ is observed. Increase in flow velocity by $4.43 \%$ is obtained when the rotation speed is changed from $1100 \mathrm{rpm}$ to $1300 \mathrm{rpm}$ by keeping other two conditions as previous. To investigate the effect of feed rate on material flow velocity, rotation speed is kept constant at $1100 \mathrm{rpm}$ and plunge pressure at $15 \mathrm{MPa}$, feed rate when changed from $22 \mathrm{~mm} / \mathrm{min}$ to $44 \mathrm{~mm} / \mathrm{min}$ increase in flow velocity by $60.12 \%$ is observed. Feed rate when changed from $22 \mathrm{~mm} / \mathrm{min}$ to $66 \mathrm{~mm} / \mathrm{min}$ by keeping other two parameters constant as previous, increase in flow velocity by $126.26 \%$ is obtained. Fig. 11 supports the above discussions.

Above discussions make it clear that material flow velocity increases when rotation speed as well as feed rate of tool increases. Increase in rotation speed causes the sever increase in heat generation which leads to the increase in temperature at preheat zone. Material present in the preheat zone becomes easy to deform with increase in temperature. This reduction in flow stress of material leads to increase in flow rate and by that assuring good mixing of material. The size of thermo-mechanically affected zone increases with feed rate, making the material easy to flow. FSW and UFSW though both showed the increase in material flow velocity, but percentage of increase is slightly more in FSW than UFSW. 


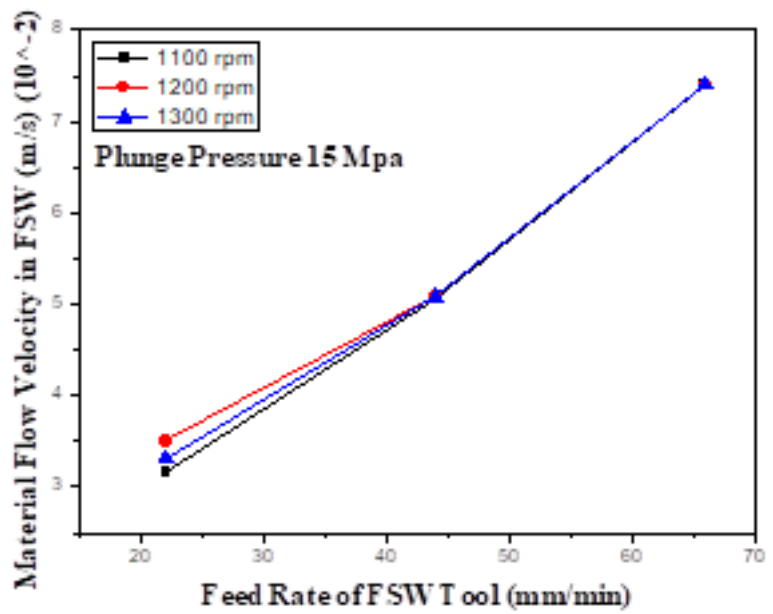

(a)

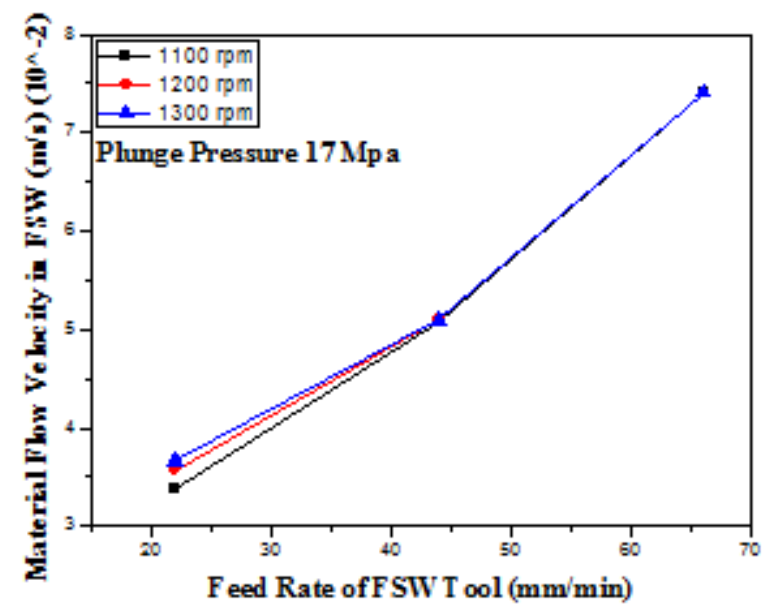

(b)

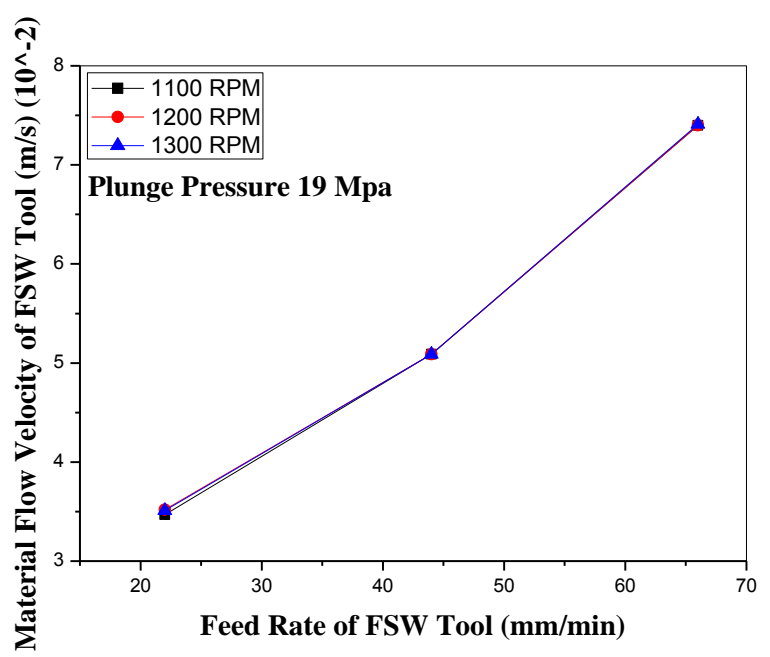

(c)

Figure 10. Material flow in FSW with Feed rate of tool at constant plunge pressure of (a) $15 \mathrm{Mpa}$ (b) $17 \mathrm{Mpa}$ (c) $19 \mathrm{Mpa}$

This is because the difference in viscosity of water and air. If the FSW is done in the environment of high viscosity fluid, then material flow gets affected. The amount of heat generation decreases which leads to increase in flow stress, since the viscosity of water is more than the viscosity of air material flow velocity of UFSW is less than the FSW.

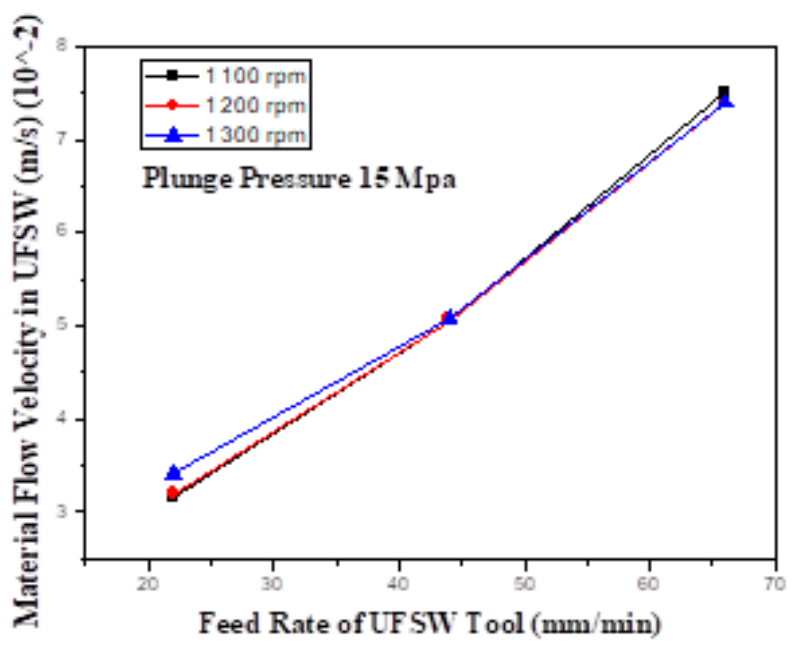

(a)

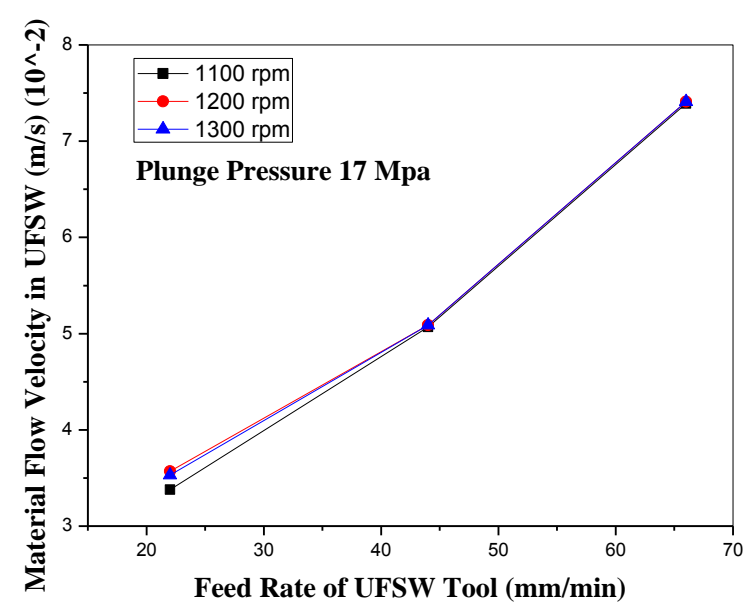

(b)

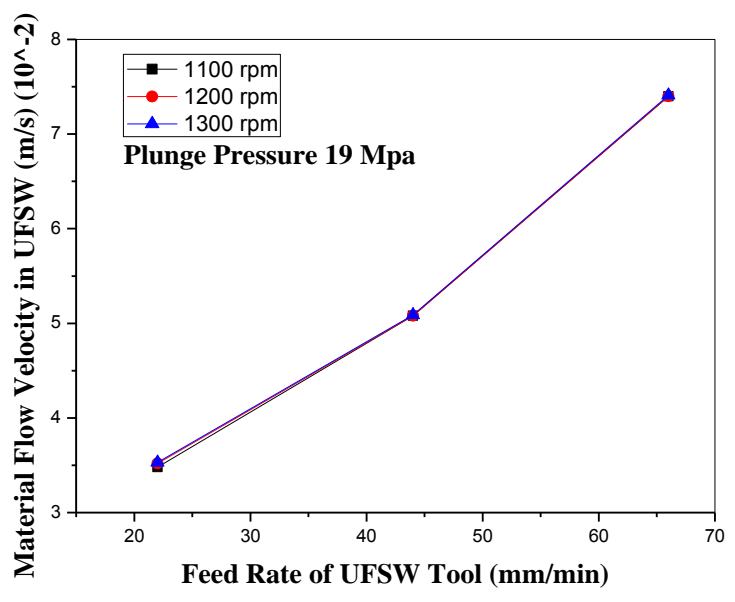

(c)

Figure 11. Material flow in UFSW with Feed rate of tool at constant plunge pressure of (a) $15 \mathrm{Mpa}$ (b) $17 \mathrm{Mpa}$ (c) $19 \mathrm{Mpa}$ 


\subsection{Effect of Strain Rate}

Strain rate plays a major role on the properties of the weld joint. Hence, in the present work the effect of strain rate at different locations is studied. Figure 12 and figure 13 shows the plots of computed temperature distribution, strain rate and viscosity along the direction perpendicular to the weld line ie transverse direction. Graphs are plotted at end of the tool pin on trailing side at different elevations

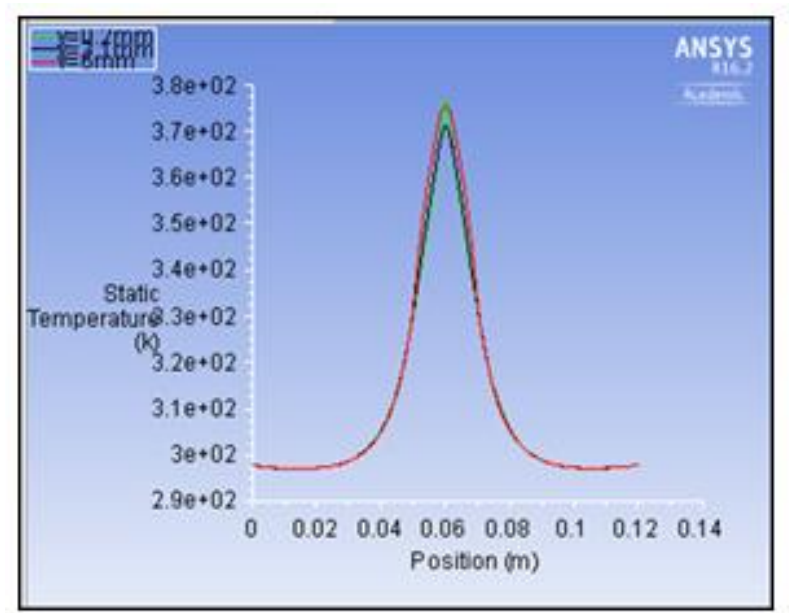

(a)

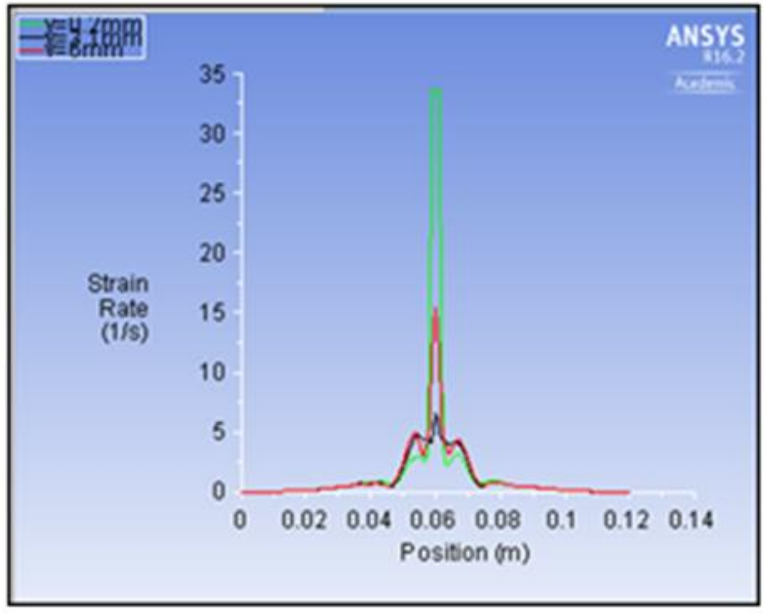

(b)

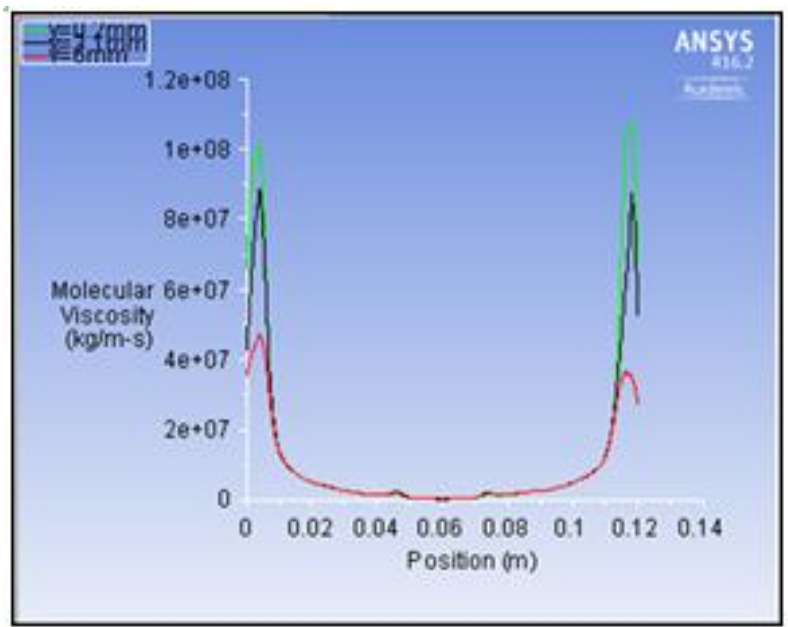

(c)

Figu re 12. Plots of (a) Temperature (b) Strain rate (c) Viscosity with respect to Distance perpendicular to weld line at $1100 \mathrm{rpm}, 22 \mathrm{~mm} / \mathrm{min}$ feed rate and 17 Mpa plunge pressure in FSW, captured on a planes at a dist ance of $\mathrm{y}=6 \mathrm{~mm}, \mathrm{y}=3.1 \mathrm{~mm}$ and $\mathrm{y}=0.2 \mathrm{~mm}$ from bot tom surface of workpiece 


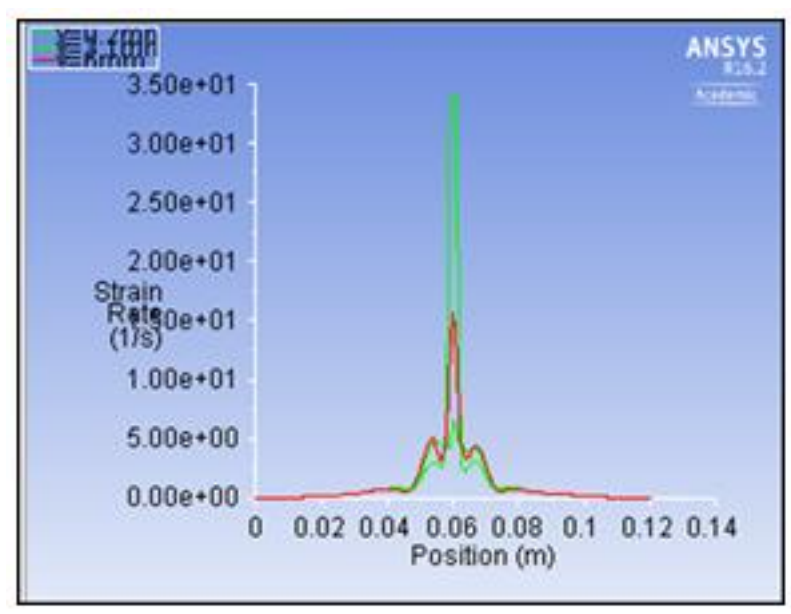

(a)

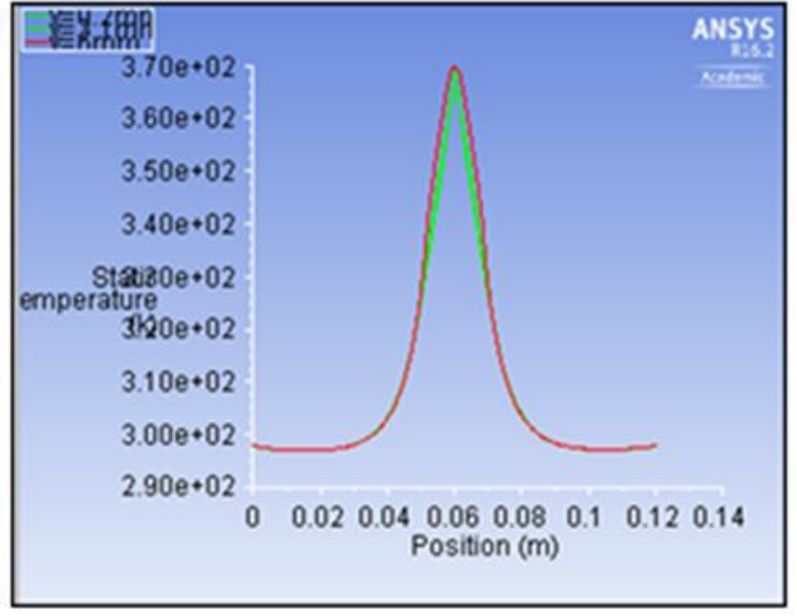

(b)

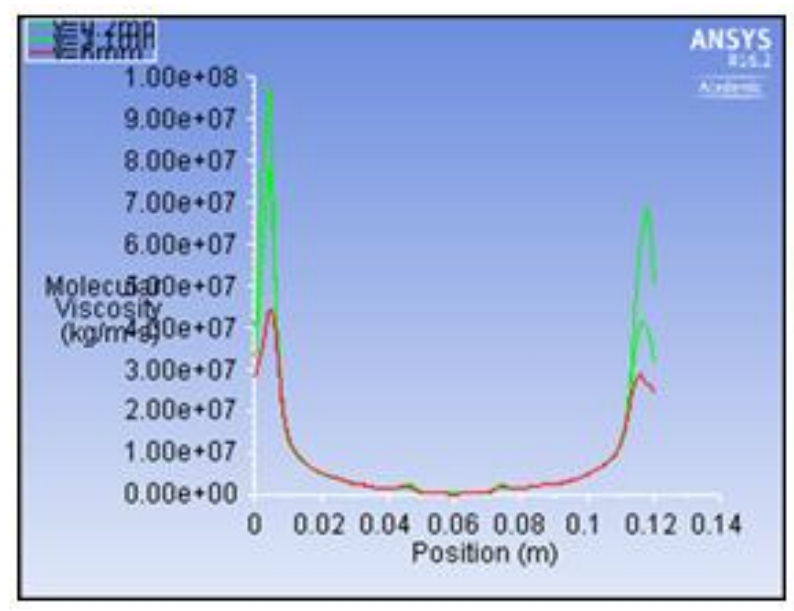

(c)

Figure 13. Plots of (a) Temperature (b) Strain rate (c) Viscosity with respect to Distance perpendicular to weld line at $1100 \mathrm{rpm}, 22 \mathrm{~mm} / \mathrm{min}$ feed rate and $17 \mathrm{Mpa}$ plunge pressure in UFSW, captured on a planes at a distance of $\mathrm{y}=6 \mathrm{~mm}, \mathrm{y}=3.1 \mathrm{~mm}$ and $\mathrm{y}=0.2 \mathrm{~mm}$ from bottom surface of workpiece

Three plains are taken at $\mathrm{y}=6 \mathrm{~mm}, \mathrm{y}=3.1 \mathrm{~mm}$ and $\mathrm{y}=0.2 \mathrm{~mm}$. The maximu $\mathrm{m}$ value of strain rate is observed to be $35 \mathrm{~s}^{-1}$ and it occurred at the near the outer surface of tool pin. At the same points, minimum value of viscosity is observed since it is inversely proportional to the strain rate. Visco-plastic Material under the shoulder shows the very less value of viscosity tending do zero and hence prove that the material in third body region shows the 3D characteristics of ideal fluid. Viscosity outside the influence of shoulder is increased slowly and attained the maximu $\mathrm{m}$ value of $1 \mathrm{e}+08$ at the retreating side. The value of viscosity is found to increased when the distance from bottom surface is decreasing at the parent material. This is because of the low values of strain rate achieved at the parent material. The high values of temperature are observed at the stir zone due to rigorous action of stirring. Temperature increases with distance from the bottom because of the high amount of plastic deformation of material.

As seen from the plots, temperature distribution in material is getting affected by the location of tool in depth direction in both FSW and UFSW. These results in the mild to severe temperature gradients in depth direction and affects the hardness of the joint in depth direction. In AA due to high thermal conductivity the regions where metal deformations have occurred they only shows the variation in hardness. Therefore, from the plots of strain rate, it is understood that the hardness variation will takes place in the stir zone and thermo-mechanically affected zone only, because of high deformation occurring in this zones. Since the temperature gradients in depth direction are different in FSW and UFSW because different cooling medium, hardness of the weld will be different.

Figure 14, 15 and 16 shows the plots of the strain rate versus distance in transverse direction on the workpiece at different planes in thickness direction. The graphs are plotted for analysing the effect of variation of rotational speed on strain rate magnitudes. Feed rate during the analysis is kept constant and so the plunge pressure. In figure 14, rotational speed is varied from $1100 \mathrm{rpm}$ to 1300 rpm by keeping feed rate and plunge pressure constant at $22 \mathrm{~mm} / \mathrm{min}$ and $17 \mathrm{Mpa}$ respectively. In the same way 
figure 15 and 16 shows the strain rate plots for $44 \mathrm{~mm} / \mathrm{min}$ feed rate, $17 \mathrm{Mpa}$ plunge pressure and $66 \mathrm{~mm} / \mathrm{min}$ feed rate, 17 Mpa plunge pressure respectively. It is observed from the figure 14 that with increase in rotational speed from $1100 \mathrm{rpm}$ to $1300 \mathrm{rpm}$ strain rate increases by $8.5 \%$. Interestingly figure 15 and 16 shows the reduction in strain rate with increase in rotational speed. The decrease is $8.3 \%$ at $44 \mathrm{~mm} / \mathrm{min}$ and $4.16 \%$ at $66 \mathrm{~mm} / \mathrm{min}$. This variation in results at high feed rate may have occurred because of reduction in plastic deformation of material. Further, the fluctuation in strain rate increases with feed rate. Since the strain rate fluctuation affects the hardness of weld this variation at high feed rate is not desirable.

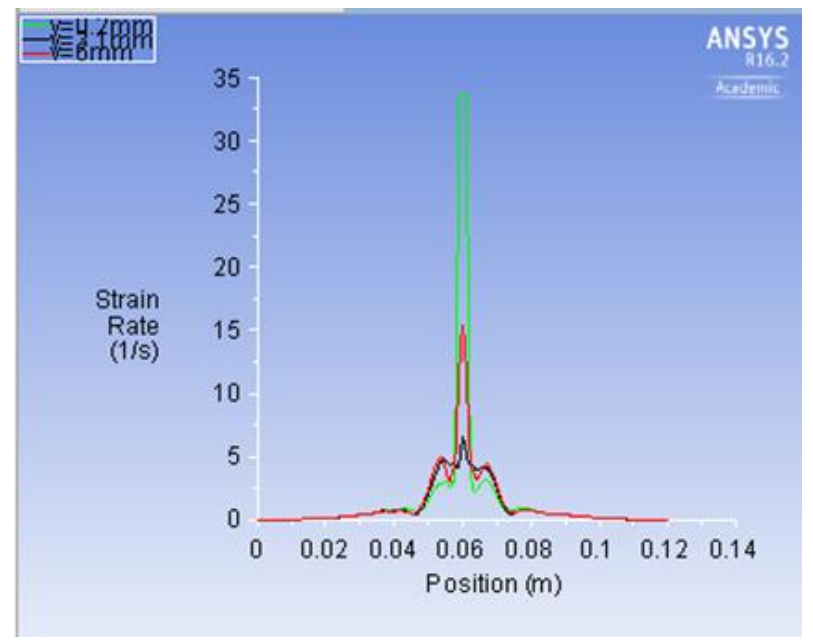

(a)

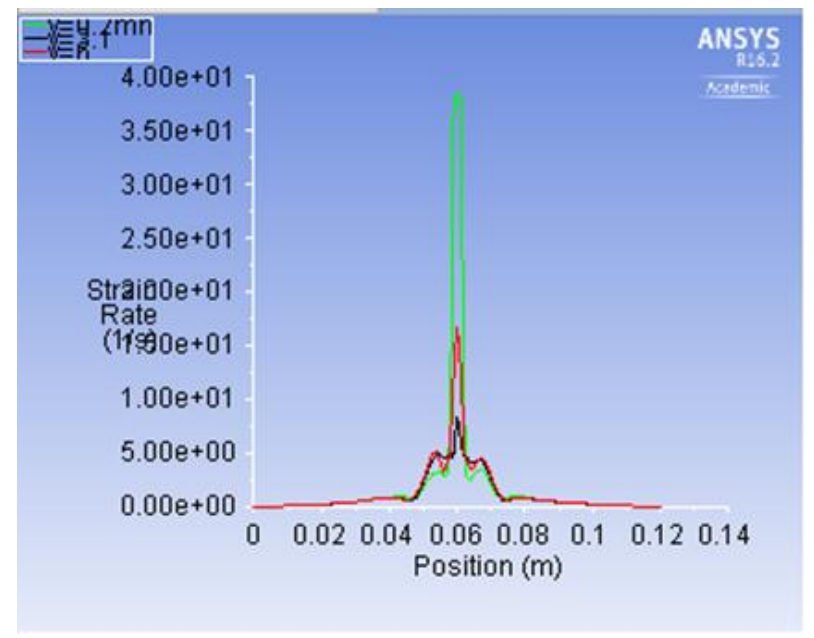

(b)

Figure 14. Plots of strain rate at $22 \mathrm{~mm} / \mathrm{min}$ feed rate and rotational speed of (a) $1100 \mathrm{rpm}$ and (b) $1300 \mathrm{rpm}$ at plunge pressure of $17 \mathrm{Mpa}$ are shown in figure 14 for FSW process

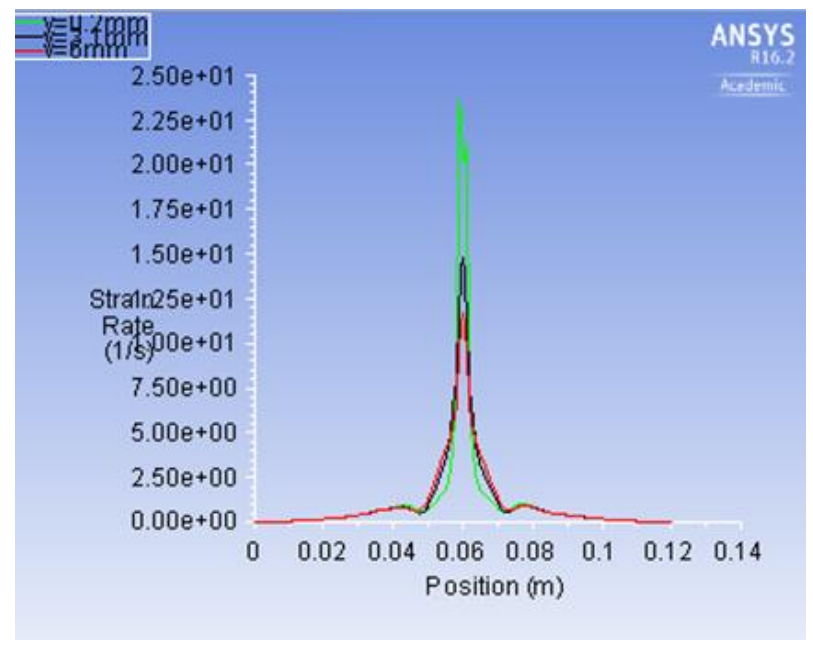

(a)

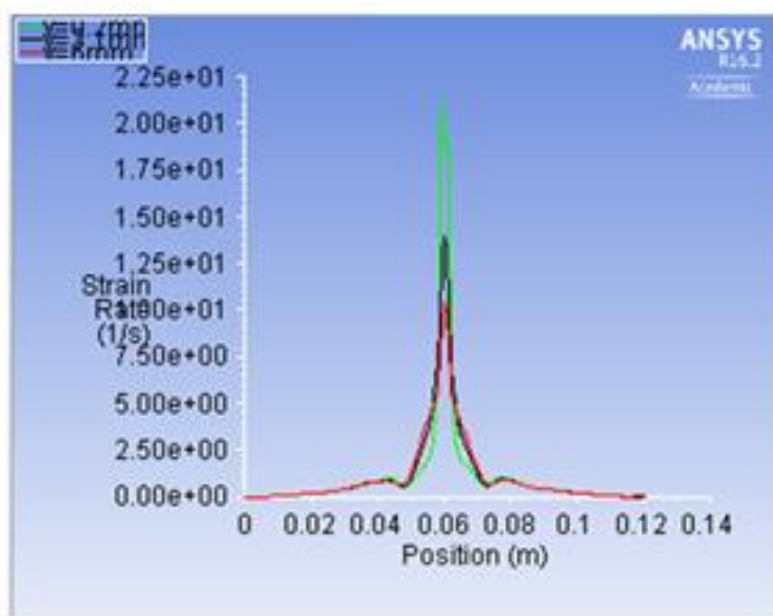

(b)

Figure 15. Plots of strain rate at $44 \mathrm{~mm} / \mathrm{min}$ feed rate and rotational speed of (a) $1100 \mathrm{rpm}$ and (b) $1300 \mathrm{rpm}$ at plunge pressure of $17 \mathrm{Mpa}$ are shown in figure 14 for FSW process.

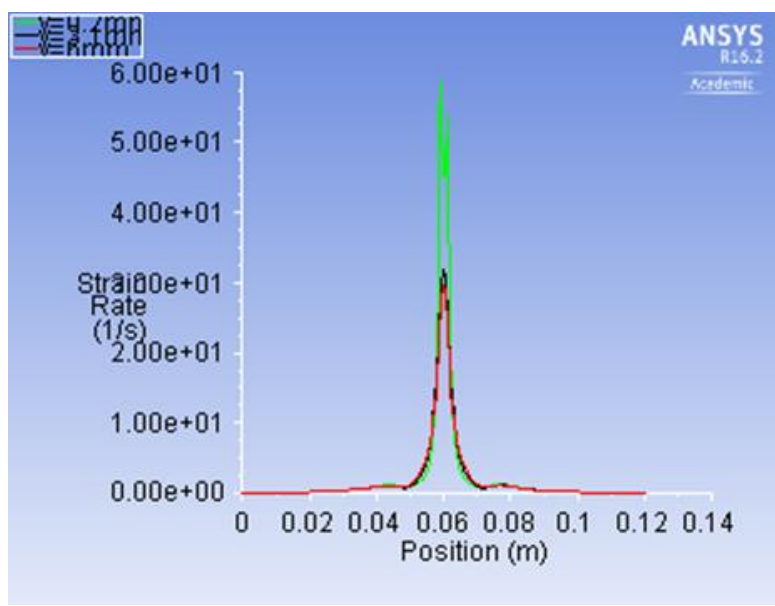

(a) 


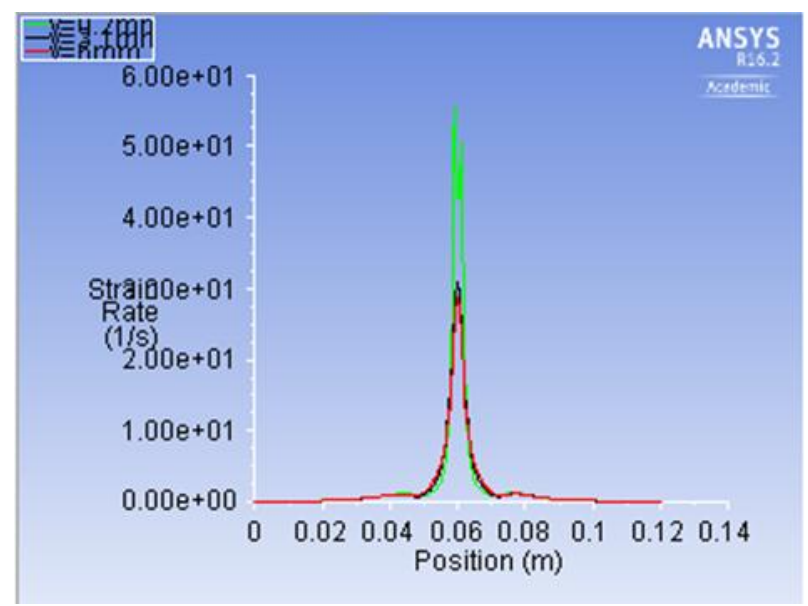

(b)

Figure 16. Plots of strain rate at $44 \mathrm{~mm} / \mathrm{min}$ feed rate and rotational speed of (a) $1100 \mathrm{rpm}$ and (b) $1300 \mathrm{rpm}$ at plunge pressure of $17 \mathrm{Mpa}$ are shown in figure 14 for FSW process

\section{Conclusions}

A combined experimental and numerical investigation is performed for FSW and UFSW process. Temperature distribution and material flow profiles are obtained from the numerical investigation. Numerical and experimental values have shown the agreement with acceptable errors. Discussions are given for the effect of influencing parameters on results of the processes. The following are the main conclusions drawn from the investigation:

- Increase in peak temperature in FSW is 5\%-6\% while in UFSW it is $2.3 \%-5 \%$, with rotation speed.

- The feed rate of tool during processes when increased, percentage reduction of $10 \%-10.7 \%$ in peak temperature occurs for FSW while for UFSW same is $8 \%-8.7 \%$.

- Material flow velocity in FSW increases by $5.9 \%-8.6 \%$ when rotation speed is increased whereas percentage is $4.4 \%-5.6 \%$ for UFSW.

- $\quad$ Feed rate when increased in FSW percentage increase in material flow velocity is $60.9 \%-134.6 \%$ and for UFSW it is $60.1 \%-126.2 \%$.

- Use of different environment during welding process affects the process outputs due to different thermomechanical properties of environment.

- At high values of feed rate ie $44 \mathrm{~mm} / \mathrm{min}$ and 66 $\mathrm{mm} / \mathrm{min}$ strain rate decreases with increase in rotational speed.

\section{REFERENCES}

[1] Arun Kumar Kadian, Pankaj Biswas, A Comparative Study of Material Flow Behavior in Friction Stir Welding Using Laminar and Turbulent Models JMEPEG (2015) 24: 4119_
4127.

[2] [LIU Hui-jie, ZHANG Hui-jie, HUANG Yong-xian, YU Lei Mechanical properties of underwater friction stir welded 2219 aluminum alloy. Trans. Nonferrous met. Soc. China 20(2010) 1387-1391.

[3] Ying Zhao, Baoyun Songa, Zhiyong Yan, Xu Zhang, Jiuy ang Pei Microstructure and mechanical properties of extrusion welds in continuous extrusion of AA6063 aluminium alloy with double billets. Journal of Materials Processing Technology 235 (2016) 149-157.

[4] S. Ugender, A. Kumar and B. Sommy Reddy Experimental investigation of tool geometry on mechanical properties of friction stir welding of AA 2014. Procedia materials science 5 (2014) 824-831.

[5] Inderjeet Singh, Gurmeet Singh Cheema, Amardeep Singh Kang An experimental approach to study the effect of welding parameters on similar friction stir welded joints of AZ31B-O Mgalloy. Procedia Engineering 97 (2014) 837 846.

[6] A. Arora, T. DebRoy, H.K.D.H. Bhadeshia, Back-of-theenvelope calculations in friction stir welding - Velocities, peak temperature, torque, and hardness Acta Materialia 59 (2011) 2020-2028.

[7] G.Q. Chen, Q.Y. Shi, Y. Fujiya, and T. Horie, Simulation of Metal Flow During Friction Stir Welding Based on the Model of Interactive Force Between Tool and Material JMEPEG (2014) 23: 1321-1328.

[8] P H Shah, Vishvesh Badheka An experimental investigation of temperature distribution and joint properties of Al 7075 T651 friction stir welded aluminium alloys. Procedia Technology 23 (2016) $543-550$.

[9] Heena K Sharma, Kamlesh Bhatt,Krunal Shah Unnati Joshi Experimental Analysis of Friction Stir Welding of Dissimilar Alloys AA6061 and Mg AZ31Using Circular Butt Joint Geometry Procedia Technology 23 ( 2016 ) 566 -572 .

[10] J Mohammadi, Y. Behnamian, A. Mostafaei, A.P. Gerlich Tool geometry, rotation and travel speeds effects on dissimilar magnesium/aluminium friction stir welded lap joints. Materials and design 75 (2015) 95-112.

[11] Zhao ZHANG, Qi WU, Hong-wu ZHANG Numerical studies of effect of tool sizes and pin shapes on friction stir welding of AA2024-T3 alloy Trans. Nonferrous Met. Soc. China 24 (2014) 3293-3301.

[12] Ramanjaneyulu KADAGANCHI, Madhusudhan Reddy GANKIDI, Hina GOKHALE Optimization of process parameters of aluminum alloy AA 2014-T6 friction stir welds by response surface methodology Defence Technology 11 (2015) 209-219.

[13] Hao Su, Chuan Song Wu, Marcel Bachmann, Michael Rethmeier Numerical modeling for the effect of pin profiles on thermal and material flow characteristics in friction stir welding Materials and Design 77 (2015) 114-125.

[14] Hua Wang, Paul A. Colegrove, Jorge F. dos Santos Numerical investigation of the tool contact condition during friction stir welding of aerospace aluminium alloy. Computational Materials Science 71(2013) 101-108 
[15] Paul A. Colegrove, Hugh R. Shercliff 3-Dimensional CFD modelling of flow round a threaded friction stir welding tool profile Journal of Materials Processing Technology 169 (2005) 320-327.

[16] [14] T. K. BHATTACHARYA, H. DAS, T. K. PAL Influence of welding parameters on material flow, mechanical property and intermetallic characterization of friction stir welded AA6063 to HCP copper dissimilar butt joint without offset. Trans. Nonferrous Met. Soc. China 25(2015) 2833-2846.

[17] S.D. Ji, Q.Y. Shi, L.G. Zhang, A.L. Zou, S.S. Gao, L.V. Zan Numerical simulation of material flow behavior of friction stir welding influenced by rotational tool geometry Computational Materials Science 63 (2012) 218-226.

[18] A.F. Hasan, C.J. Bennett, P.H. Shipway A numerical comparison of the flow behaviour in Friction Stir Welding (FSW) using unworn and worn tool geometries. Materials and Design 87 (2015) 1037-1046.

[19] H.I Dawood, Kahtan S. Mohammed, Azmi Rahmat, M.B. Uday Effect of small tool profile on microstructure and mechanical properties of 6061 Aluminum alloy by friction stir welding. Trans. NonFerrous Met. Soc. China 25 (2015) 2856-2865

[20] M. Koilraj, V. Sundareswaran, S. Vijayan, S.R. Koteswara Rao Friction stir welding of dissimilar aluminum alloys AA2219 to AA5083 - Optimization of process parameters using Taguchi technique. Materials and Design 42 (2012) $1-7$.

[21] Rui-dong Fu, Zeng-qiang Sun, Rui-cheng Sun, Ying Li, Huijie Liu, Lei Liu Improvement of weld temperature distribution and mechanical properties of 7050 aluminum alloy butt joints by submerged friction stir welding Materials and Design 32 (2011) 4825-4831.

[22] H.J. Liu, H.J. Zhang, L. Yu Effect of welding speed on microstructures and mechanical properties of underwater friction stir welded 2219 aluminum alloy. Materials and Design 32 (2011) 1548-1553.

[23] Huijie Zhang, Huijie Liu Mathematical model and optimization for underwater friction stir welding of a heattreatable aluminum alloy. Materials and Design 45 (2013) 206-211.

[24] H.J. Zhang, H.J. Liu, L. Yu Microstructure and mechanical properties as a function of rotation speed in underwater friction stir welded aluminum alloy joints. Materials and Design 32 (2011) 4402-4407.

[25] LIU Hui-jie, ZHANG Hui-jie, HUANG Yong-xian, YU Lei Mechanical properties of underwater friction stir welded 2219 aluminum alloy. Non Ferrous Met. Soc. China 20 (2010) 1387-1391.

[26] FRATINI L, BUFFA G, SHIVPURI R. In-process heat treatments to improve FS-welded butt joints [J]. International Journal of Advanced Manufacturing Technology, 2009, 43(7-8): 664-670.

[27] Hui-jie ZHANG, Hui-jie LIU, Lei YU Thermal modeling of underwater friction stir welding of high strength aluminum alloy. Trans. Nonferrous Met. Soc. China 23(2013) 11141122 .
[28] Chun-lei GAN, Kai-hong ZHENG, Wen-jun QI, Meng-jun WANG Constitutive equations for high temperature flow stress prediction of $6063 \mathrm{Al}$ alloy considering compensation of strain. Trans. Nonferrous Met. Soc. China 24(2014) 3486-3491.

[29] L. Shia, C.S. Wua, X.C. Liu Modeling the effects of ultrasonic vibration on friction stir welding. Journal of Materials Processing Technology 222 (2015) 91-102.

[30] D.Roncati Iterative calculation of the heat transfer coefficient. Progettazione Ottica Roncati, Italy (2013). 